\title{
Effusion rate controls on lava flow length and the role of heat loss: a review
}

\author{
A. J. L. HARRIS ${ }^{1} *$ \& S. K. ROWLAND ${ }^{2}$ \\ ${ }^{1}$ Hawaii Institute of Geophysics and Planetology, School of Ocean and Earth Science and \\ Technology, University of Hawaii at Mānoa, 1680 East-West Road, Honolulu, HI 96822, USA \\ ${ }^{2}$ Department of Geology and Geophysics, School of Ocean and Earth Science and Technology, \\ University of Hawaii at Manoa, 1680 East-West Road, Honolulu, HI 96822, USA \\ *Corresponding author (e-mail: a.harris@opgc.univ-bpclermont.fr)
}

\begin{abstract}
Walker (1973; Phil. Trans. R. Soc. Lond., 274, 107) argued that, for a limited set of compositions and flow types, effusion rate $(E)$ was the principal influence on flow length, sparking a series of studies into the volume and cooling limits on flow extension. We here review these works, as well as the role of heat loss in controlling flow length. We also explore the applicability of Walker's idea to a larger compositional and morphological range. Heat loss plays a fundamental role in determining flow core cooling rates, thereby influencing cooling-limited flow length. Field measurements allow classification of four flow types with respect to heat loss. In this classification as we move from poorly insulated to well insulated regimes, decreased heat losses increase the length that a flow can extend for a given $E$, composition, morphology, or amount of cooling: (1) immature tube-contained, basalt - thin tube roofs provide minimal insulation, allowing cooling rates of $c .10^{-2}{ }^{\circ} \mathrm{C} \mathrm{s}^{-1}$ so that at low $E$, these flows extend only a few hundred metres; (2) poorly crusted, basalt - open channels with hot surface crusts also exhibit cooling rates of c. $10^{-2}{ }^{\circ} \mathrm{C} \mathrm{s}^{-1}$ so such flows extend a few kilometres at $E<1 \mathrm{~m}^{3} \mathrm{~s}^{-1}$; (3) heavily crusted, dacite - heat losses are reduced when thick crusts form, reducing core cooling rates to c. $10^{-4}{ }^{\circ} \mathrm{C} \mathrm{s}^{-1}$ so these flows can potentially extend several kilometres even at low $E$ and despite very high viscosities $\left(10^{9}-10^{10} \mathrm{~Pa} \mathrm{~s}\right)$; (4) master tube-contained, basalt - thick tube roofs insulate flow, reducing heat losses and cooling rates to $c .10^{-3}{ }^{\circ} \mathrm{C} \mathrm{s}^{-1}$. These cooling rates mean that at low $E$, tube-contained flows can extend tens to hundreds of kilometres. Basically, if composition, insulation, and morphology are held constant flow length will increase with effusion rate.
\end{abstract}

Our aim is to review G. P. L. Walker's pioneering work into the emplacement of lava flows, focusing on his studies of the relationship between effusion rate and eventual flow length, and the subsequent work that this inspired. Walker's ideas on this topic followed observations of active lava flow emplacement during a terminal (summit) effusive eruption at Mt Etna (Italy) during 1966, and the work was completed during 1967-1973. The work comprised a series of three papers. The first, 'Thickness and viscosity of etnean lavas' (Walker 1967), was published in Nature and examined the influence of viscosity and slope on flow emplacement, dimensions and morphology. The second, 'Compound and simple lava flows and flood basalts' (Walker 1972), published in Bulletin of Volcanology, set up standard definitions and nomenclature for lava flow units and compound lava flows, and examined the conditions under which different flow architectures are built. Finally, 'Lengths of lava flows' (Walker 1973; in the Philosophical Transactions of the Royal Society of London) rounded the series off by demonstrating that effusion rate is the principal factor that influences not only flow length, but also flow field type, with viscosity being a secondary factor. With higher effusion rates, long simple flows tend to be emplaced, whereas at lower effusion rates, multiple short flows pile up around a vent to build compound flow fields.

We focus on the main theme of this third paper and the influence that this has had on subsequent study and debate, before examining the role of thermal insulation and heat loss on determining and modifying effusion rate-flow length relationships. A relationship that governs the interplay between flow length, heat loss and effusion rate was recognized by Walker (1973). In the conclusion of the 'Lengths of lava flows' paper he stated:

There seems to be a tendency for the relatively highfluidity pahoehoe flows to be shorter than the somewhat more viscous aa flows, and it was this tendency which first suggested to the author that some factor other than viscosity controls the lengths of lava flows ... This tendency, if real, could be related to a relatively high rate of heat loss per unit volume from thin flows of pahoehoe as compared with 
thicker flows of aa. The strong tendency for the former to build up compound lavas could be due to the same cause.

This elegant statement sums up the complexities involved in determining how far a flow can extend, with effusion rate, rheology, heat loss, flow morphology and eruption duration all playing roles, and all being subject to complex feedbacks with each other. Heat loss, for example, will determine cooling rates and hence temperature-dependent viscosity and velocity, eventually limiting a flow's ability to move. Velocity in turn will influence the coherence of the surface crust, thereby affecting heat loss. Because of this complex interplay it is unlikely that flow length can be attributed to individual flow parameters in a universal way. Instead, different cases defined by specific rheological, heat loss and/or emplacement conditions need to be considered separately.

\section{Definitions}

An important distinction in this review is between flow unit, simple lava flow, compound lava flow and compound lava flow field. Following Walker's (1972) definition, the smallest component of a lava body is a flow unit. This, following Nichols (1936), can be defined as having 'a top which cooled significantly and solidified (as shown by the fact that it is chilled and has its own set of contraction cracks) before another flow-unit was superimposed on it' so that 'each flow-unit is a separate cooling unit' (Walker 1972). A simple lava flow is a flow that consists of only one to a few individual flow units or branches that are much longer than they are wide (e.g. Kilburn \& Lopes 1988). Typically they develop during short eruptions that have effusion rates that decrease rapidly from an initially high rate (e.g. Wadge 1981). Examples are the 1981 Etna flow (Guest et al. 1987), most channel-fed aa flows in Hawaii (Rowland \& Walker 1990) and in general the Type A flows of Wadge et al. (1994).

A compound lava flow, on the other hand, is divisible into many flow units (Walker, 1972). A long-lived eruption may, however, comprise many compound lava flows, each emplaced during a specific eruption episode or in a particular location (Mattox et al. 1993). The ultimate extension of this classification is thus a compound lava flow field, this being the product of every compound lava flow erupted during the entire eruption. A specific example is the current eruption of Kilauea, where a compound lava flow field comprises multiple compound lava flows emplaced during Episodes 48, 50, 51, 52, 53, 55 and 58, each lasting more than a year (Heliker \& Mattox 2003). An additional example is the July-August
2001 Etna compound lava flow field, which comprises seven individual compound lava flows erupted from seven different fissures (e.g. Behncke $\&$ Neri 2003). Compound lava flow fields can be produced by eruptions dominated by essentially constant, but low effusion rate emission, lasting for months to years to build fields with low length:width ratios (Kilburn \& Lopes 1988), or can be produced by shorter duration eruptions from multiple vents. Most compound lava flow fields would be considered Type $\mathrm{B}$ flows by Wadge et al. (1994).

It is also important to distinguish between effusion rate, time-averaged discharge rate, eruption rate and mean output rate. Here, we follow the definitions set out in Harris et al. (2007) whereby effusion rate $(E)$ is the volume flux of erupted lava that is feeding a flow at any particular point in time. It is sometimes also called the instantaneous effusion rate, and is often obtained by multiplying mean flow velocity $\left(\varpi_{\text {mean }}\right)$ by flow cross-sectional area $\left(A_{\text {cross }}\right)$. Time-averaged discharge rate (TADR) considers multiple effusion rates averaged over given time periods. Eruption rate $\left(E_{\mathrm{r}}\right)$ is the total volume of lava emplaced since the beginning of the eruption divided by the time since the eruption began, with the ultimate extension being the mean output rate (MOR), this being the total erupted volume divided by the total eruption duration. Mathematically we can define these rates as follows.

1. Effusion rate $(E)=\delta V / \delta t$

2. Time-averaged discharge rate $(\mathrm{TADR})=$ $\left[V\left(t_{2}\right)-V\left(t_{1}\right)\right] /\left[t_{2}-t_{1}\right]$

3. Eruption rate $\left(E_{\mathrm{r}}\right)=V\left(t_{x}\right) / t_{x}$

4. Mean output rate (MOR) $=V_{\text {total }} / t_{\text {total }}$

Here $t$ is time, $t_{x}$ is time since the beginning of the eruption, $t_{\text {total }}$ is time at the end of the eruption, $V$ is volume, $V(t)$ is the volume erupted since time $t$ and $V_{\text {total }}$ is the final (total) erupted volume.

A critical factor with respect to lava emplacement is the process that causes a flow to stop. Most simple, channelized lava flows are cooling limited (Guest et al. 1987; Pinkerton \& Wilson 1994; Wright et al. 2001), meaning that heat losses cause the lava to lose its ability to flow beyond a particular distance regardless of the duration of supply from the vent. This maximum distance is almost always attained during the early part of the eruption (e.g. Walker 1973). Conversely, volume-limits occur when supply ceases before the full cooling-limited length can be attained (Guest et al. 1987).

Note that under these definitions an individual pahoehoe flow unit is usually cooling limited. However, Swanson (1973) described near-vent pahoehoe flow units that stopped moving when the lava column feeding them withdrew down the vent; they therefore were volume-limited. A tube-fed 
pahoehoe flow field as a whole is usually volume limited. For example, Mauna Loa's 1880-1881 eruption produced a $47 \mathrm{~km}$-long compound, tubefed, pahoehoe flow field (Rowland \& Walker 1990). As long as the eruption continued, the tube developed down slope and fed a distal zone of active pahoehoe flow units; each of these flow units was cooling limited. However, shortly after the eruption ended, the tube drained and the distal zone was robbed of supply; additional advance of the flow field as a whole was therefore volumelimited. Based on cooling/distance values of $1{ }^{\circ} \mathrm{C} \mathrm{km}^{-1}$ (from data in Swanson 1973; Keszthelyi 1995) or $0.5^{\circ} \mathrm{C} \mathrm{km}^{-1}$ (Clague et al. 1999), a temperature drop of $200-400{ }^{\circ} \mathrm{C}$ to cause a basalt flow to stop moving (see below), and given an unlimited sub-aerial surface and unlimited eruption duration, the 1880-1881 Mauna Loa pahoehoe flow field theoretically could have reached a cooling-limited length of 400-800 km.

\section{Lengths of lava flows: a review}

Walker's (1973) 'Lengths of lava flows' was a landmark paper. Malin (1980) describes it as 'pioneering work' which, by linking lava flow length and effusion rate, questioned the common belief at the time that flow length depended solely, or at least principally, upon viscosity. Instead, to quote from the abstract of Walker (1973), 'the principal factor influencing the length of a lava flow is the rate of effusion'. In his 1973 work Walker plotted, for 41 flows of three different compositions at 19 different volcanoes, flow length against what he termed 'average rate of effusion' (which, using the terms defined above, would be considered as a MOR; Fig. 1). He omitted eruptions with durations $<30 \mathrm{~h}$ and longer than 9 months, and we discuss the rationale for these omissions below. He concluded that

although there is a scatter of points, it is striking how good is the correlation between length of flow when one bears in mind that the data are drawn from different volcanoes, involving lavas differing in initial viscosity by a factor of 1000 Poise or more, which have come down slopes varying from 1 to 30 degrees, and based on volume estimates probably of varying degrees of reliability.

Walker (1972) postulated that with a high effusion rate, lava tended to flow rapidly away from the vent to form a long simple flow. In contrast, a low effusion rate favoured formation of a compound lava flow field. In Walker (1973), he stated that the importance of effusion rate on influencing flow length had become apparent to him on Etna during his 1966 observations of flow emplacement (described in Walker 1967). These observations revealed that low effusion rate flows had life spans of only minutes to hours (despite the fact that the overall eruptions lasted for days to weeks) whereas higher effusion rates led to individual flows that were active for hours to days. In Walker's words,

a lava stream with a cross-sectional area immediately below its bocca of less than about $1 \mathrm{~m}^{2}$ (giving a flow rate of less than about $0.2 \mathrm{~m}^{3} \mathrm{~s}^{-1}$ ) was found to

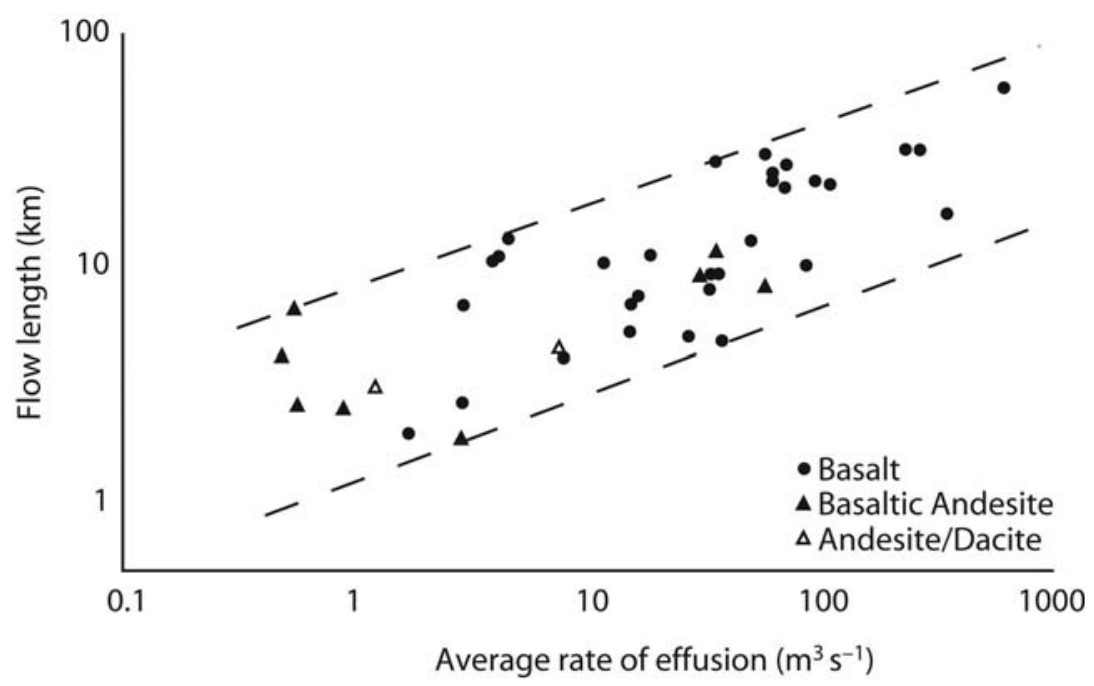

Fig. 1. Figure 4 of Walker (1973) giving a 'lava length versus average effusion rate for lava eruptions (mostly basaltic) on various volcanoes' (Walker, 1973). Walker's (1973) effusion rate is actually a mean output rate (total volume/total duration). 
have a life of minutes or hours to travel at most only a few tens of metres, whereas one with a cross-sectional area of 2 to $3 \mathrm{~m}^{2}$ (flow rate about $1 \mathrm{~m}^{3} \mathrm{~s}^{-1}$ ) could flow for a day or more and reach a distance of the order of $1 \mathrm{~km}$ from its bocca. (Walker 1973)

Here again, however, we encounter a complication, where one might ask - was it the effusion rate that mattered, the effusion duration, or both? It obviously was not possible to isolate the two factors low effusion toes were only fed for a short time, whereas higher-effusion simple flows were fed for longer durations.

These papers influenced and directed a subsequent body of literature aimed at explaining and quantifying the volume and cooling limits on lava flow emplacement, either through empirical
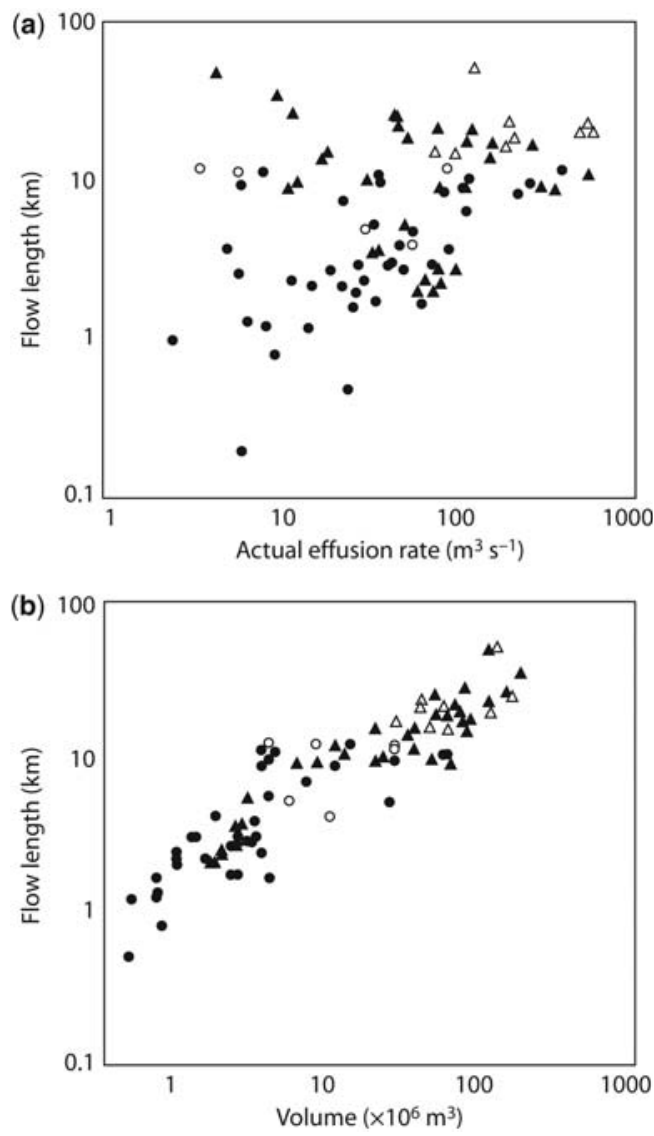

Fig. 2. Figures 2 and 3 of Malin (1980) giving (a) lava flow length v. 'actual effusion rate' (or eruption rate) and (b) flow length v. subaerial volume for Hawaiian basaltic flows. Circles are data for Kilauea, and triangles are for Mauna Loa, where open symbols indicate cases where the flow entered the ocean. analysis (measurement of dimensional, rheological and slope parameters followed by correlation) and/or theoretical treatment (e.g. heat loss or rheological modelling). What follows is a summary of this subsequent work, including: (i) refinements to Walker's effusion rate definition and the effect of lava tubes; (ii) the effects of short duration, volume-limited flow; and (iii) compound flow fieldforming eruptions with long durations and variable effusion rates.

\section{Refinements to the effusion rate definition and the effect of lava tubes}

Malin (1980) defined what he termed the 'actual effusion rate' as the volume of a flow unit divided only by the time that it was active, differing from Walker's (1973) mean output rate, which, as noted above, is the volume of an entire flow divided by the entire eruption duration. Malin (1980) pointed out that, if this actual effusion rate is used, then at least for the Hawaiian flows he studied, the correlation with flow length mostly disappears (Fig. 2a). This is partly because: (1) the emplacement time of an individual flow unit is usually less
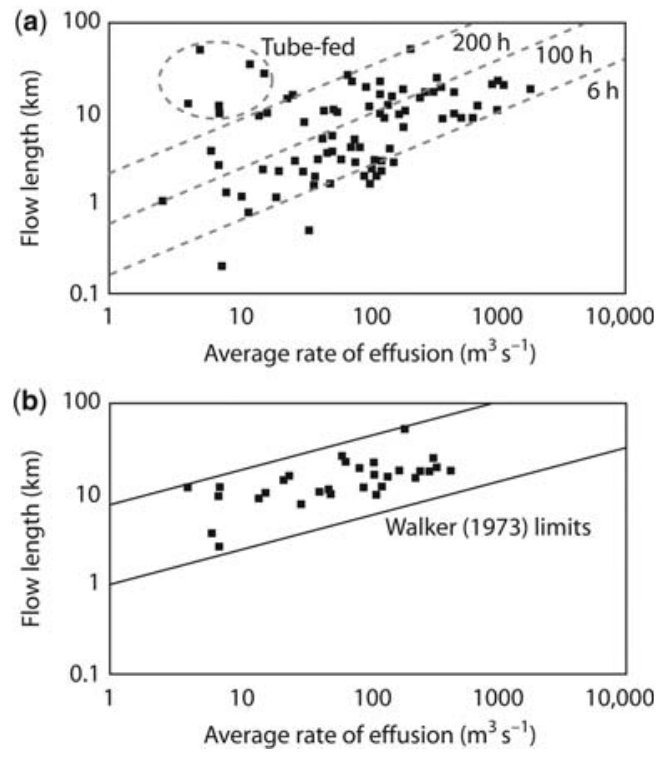

Fig. 3. Figures 1 and 2 of Pinkerton \& Wilson (1994) giving (a) Malin's (1980) data showing the relationship between flow duration, length and eruption rate, as well as tube-fed cases, and (b) Malin's (1980) data for high duration $(>45 \mathrm{~h}$ ) channel-fed flows only (i.e. tube-fed cases and short duration flows identified in (a) have been omitted), with the original limits of Walker (1973) given by the solid lines. 
than the duration of an entire eruption; (2) effusion rates decrease during an eruption, and most of a flow is emplaced during the initial high effusion-rate phase; and (3) many of the Hawaiian flows Malin analysed were tube-fed. For Hawaiian flows, Malin found instead that flow length $(L)$ correlated better with volume $(V)$, in a power law relationship, with $L$ being proportional to $V^{0.5}$ (Fig. 2b).

In a re-examination of Malin's (1980) Hawaiian data, Pinkerton \& Wilson (1994) found that a relationship between time averaged discharge rate (TADR; note this is not the same as Malin's actual effusion rate) and flow length held if the limits initially stated by Walker (1973) were applied: tube-fed flows (i.e. those lasting $>9$ months) as well as flows of durations $<30 \mathrm{~h}$ need to be omitted (Fig. 3a). Large master tubes insulate lava more effectively than do channels (e.g. Swanson 1973; see below), producing much less of a cooling limit for a given TADR. Short duration flow may be volume limited, meaning that the supply terminates before the full cooling-limited potential is attained. Inclusion of these cases will therefore also cause the relationship to break down because the Walker (1973) relationship requires that the full, cooling-limited extent be attained. Exclusion of tube-fed flows and consideration of channel-fed flows of greater than $30 \mathrm{~h}$ in duration (i.e. there is no volume limit) returns us to a scenario in which, as argued by Walker (1973), high effusion rate flows have the potential to flow farther than low effusion rate flows before cooling prevents additional advance (Fig. 3b).

\section{The effects of short duration, volume-limited flow}

The above consideration points not only to the effect of master tubes, which allow low effusion rate flows to extend great distances, but also to shorteruption-derived volume limits, which have the opposite effect.

1. The cooling-limited case - as argued by Walker (1973), high effusion rate flows cool proportionately less as a function of distance than those erupted at lower rates. High effusion rate flows thus have the potential to attain greater distances than low effusion rate flows. Hence, in channel-fed cases, there will be a positive relationship between effusion rate and flow length, as long as supply is maintained. For example, Etna's 1983 flow falls well within Walker's bounds (Fig. 4), indicating that it was cooling limited (Guest et al. 1987).

2. The volume-limited case - in the volumelimited case, flow stops before the maximum (cooling-limited) extent is attained because the supply ceases. Such flows will thus not fit the Walker (1973) trend because the relationship depends on the full cooling limited extent being attained. For example, Etna's 1981 flow falls at the lower edge of Walker's bounds (Fig. 4), probably indicating that its extension was influenced by limited supply (Guest et al. 1987). The other aspect of the volume-limited case is illustrated by eruptions

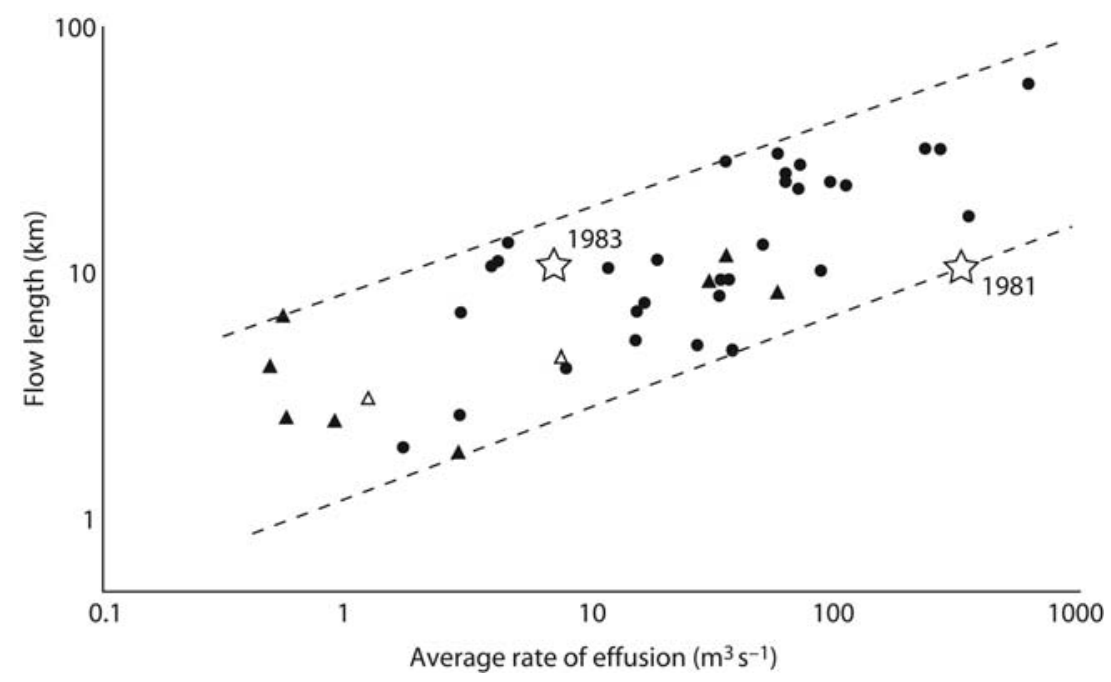

Fig. 4. Walker's (1973) flow length versus mean output rate plot with the 1981 and 1983 Etna flow fields added using stars (following Guest et al. 1987). See Figure 1 for key. 
that last long enough to develop long master tubes. Here, flows with low effusion rates manage to extend much farther than they would otherwise be expected to from the Walker (1973) relationship, because heat loss from these lava tubes is so minimal.

\section{The effects of variable effusion rate and long duration, compound flow field \\ forming eruptions}

On the basis of an empirical best fit to mean output rate (MOR) and length $(L)$ for 13 flank and summit eruptions at Etna, Wadge (1978) showed that MOR $=4.8 L$ (Fig. 5b). Wadge (1978) pointed out that this relationship relied on the flows being cooling-limited (i.e. effusion rate is maintained long enough for the flows to attain their maximum length), and that the relationship therefore did not apply to tube-fed pahoehoe.

Additionally, during most long-duration eruptions, effusion rate is variable (e.g. Wadge 1978, 1981). As a result, flows in a sustained eruption have the potential to achieve a greater or lesser distance depending on the particular effusion rate supplying them, so that the cumulative result of emplacing many flow units at different effusion rates is to generate a complex shape or flow field plan (Wadge 1978). This significantly complicates a straightforward relationship between flow field length and mean output rate. Relationships that consider eruption rate, eruption duration, flow field length, width and area are required as the flow field becomes increasingly complex. Similar relationships and limits have been argued by a number of other authors. Using data for all historical eruptions at Etna at the time (102 eruptions spanning 693 BC to 1974), Romano \& Sturiale (1982) found a reasonable correlation between the total volume of lava erupted and flow field length (Fig. 5a). A stronger correlation was apparent between volume and flow field area (Romano \& Sturiale 1982). Frazzetta \& Romano (1984) used the same historical eruption data for Etna as well as data for the 1983 eruption to show that two trends could be identified in the Romano \& Sturiale (1982) volume-length relationship (Fig. 5a). The first trend had a correlation coefficient $(r)$ of 0.9 and applied to 'paroxysmal' eruptions, these being relatively short-lived, high effusion rate eruptions that generally produced 'a thin lava stream only [simple lava flow of Walker (1972)] sometimes with a few limited superimposed flow-type phenomena'. The second trend had a correlation coefficient of 0.82 and applied to 'quiet' eruptions. These were characterized by relatively long durations and low effusion rates, to build thicker flow fields of many superposed
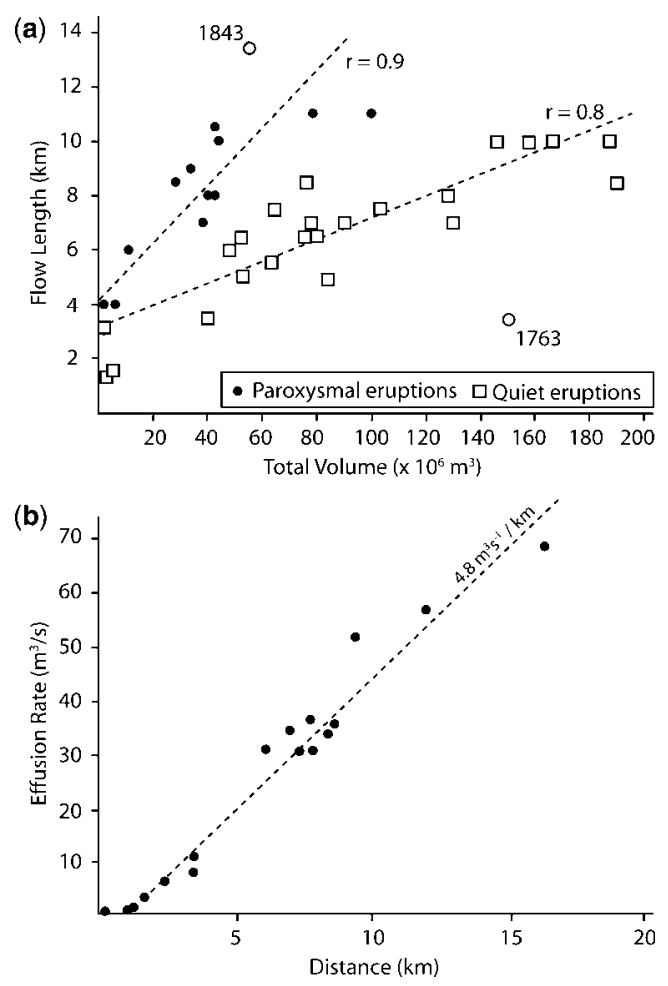

Fig. 5. (a) Figure 6 of Romano \& Sturiale (1982) showing the relationship between flow length and total volume for 37 compound lava flow fields at Etna. Two trends are apparent, one for paroxysmal eruptions (filled circles) and one for quiet eruptions (open squares) (Frazzetta \& Romano 1984). Two eruptions were considered outliers (open circles): (1) the 1763 eruption, during which particularly viscous lava was erupted to form a very thick $(50 \mathrm{~m})$ but not very extensive flow, and (2) the 1843 flow, which appeared particularly fluid, explaining its anomalous length when compared with the volume of material emitted (Romano \& Sturiale 1982).

(b) Figure 1 of Wadge (1978) showing mean output rate v. maximum distance from vent for 13 Etna eruptions.

flows. This strengthens the argument that the simple and compound flows behave differently, justifying Walker's (1973) exclusion of long duration cases.

Baloga \& Pieri (1986) took this point farther by showing theoretically that time varying flow depth, effusion rate and viscosity conditions at the source can significantly influence the final flow field dimensions and morphology, to generate scatter in plots of effusion rate versus length. This supported Walker's (1973) initial hypothesis that scatter in the effusion rate - length relationship resulted from syn-eruption variations in effusion rate (Baloga \& Pieri 1986). 
Kilburn \& Lopes (1988) continued this development by showing that eruptions of long duration and low mean output rates tend to build increasingly complex flow fields with increasing width/length ratios. Factors such as bifurcation due to levee breaching or channel overflow can generate new flows randomly, contributing to complexities in flow plan area and dimensional relationships (Kilburn \& Lopes 1988). For 69 Etna flows, Kilburn \& Lopes (1988) showed that flow field length and width both generally increase with area. The relationship back to eruption rate can be assessed using a simple relationship whereby mean flow field area $\left(A_{\text {field }}\right)$ is related to mean flow field length $\left(L_{\text {field }}\right)$ and mean width $\left(W_{\text {field }}\right)$ by

$$
A_{\text {field }}=n W_{\text {field }} L_{\text {field }}
$$

in which $n$ is a shape factor (Kilburn \& Lopes 1988). This can be expressed in terms of eruption rate $\left(E_{\mathrm{r}}\right)$ by multiplying by flow field thickness $\left(H_{\text {field }}\right)$ and dividing by time since the eruption began $\left(t_{\mathrm{x}}\right)$,

$$
E_{\mathrm{r}}=\left(n W_{\text {field }} L_{\text {field }} H_{\text {field }}\right) / t_{\mathrm{x}}
$$

Given a stable eruption rate, once the flow field has reached its maximum cooling limited length (which will likely happen within a few days of the eruption onset) the increase in $t_{\mathrm{x}}$, as the eruption progresses, is accommodated by increases in $W_{\text {field }}, H_{\text {field }}$, or both. That is, after a particular time, volumetric expansion by thickening and/or widening will dominate over lengthening.

With time, the flow field morphology and dimensions become increasingly more complex. Therefore the simple effusion rate-length relationship does not work for mean output rates and overall dimensions of compound flow fields emplaced during long-lived eruptions. As a result, in the flow field data for 25 Etnean cases, Murray $\&$ Stevens (2000) found a very poor $(r=13 \%)$ correlation between flow field length and mean output rate. Instead the best relationships considered total flow field volume $(V)$ and eruption duration $(D)$, height below the volcano summit $(h)$, or between $V$ and mean flow field area, mean width and flow field enclosure angle $(\theta)$. Essentially: $V=4.6 \times 10^{-4} \mathrm{Dh}$ or $V=2800 A_{\text {field }} W_{\text {field }} / \theta$. Both relationships have an $R$ of $c .0 .9$ (Murray \& Stevens 2000).

In summary, therefore, Walker's (1973) relationship appears to be an excellent approximation for the cases for which it was proposed to apply, that is, for single, cooling-limited, simple flows lacking tubes. With time, and variations in effusion rate, an increasingly complex, compound, flow field may develop, and expansion by widening and thickening will take over from initial length-dominated extension. Where flux is variable through time, and becomes distributed among many units, additional modifications to the straightforward effusion ratelength relationship occur, so that multivariate relations between volume, area, length, width, thickness, shape and underlying slope become more appropriate.

\section{Effusion rate-flow length relationships for simple flows}

If we avoid all the complications noted above, and only consider channel-fed, cooling limited, simple flows, and also use the time-averaged discharge rate for those individual flows, then good positive relationships between TADR and flow length can be obtained. Pinkerton \& Wilson (1994) found that for channel-fed simple flows emplaced at relatively stable TADR during early episodes of the Puu Oo (Kilauea) eruption, the best fit equation was

$$
L=0.66(\mathrm{TADR})^{0.5} t_{\text {flow }} 0.8 \quad(R=0.83)
$$

with $t_{\text {flow }}$ being the emplacement duration of only the simple flow being considered. Scatter in the relationship resulted from differences in the underlying slope $(\alpha)$ as well as the flow's thickness ( $H$; a proxy for the lava yield strength). Including these yielded

$$
\begin{array}{r}
L=1.32(\mathrm{TADR})^{0.47} t_{\text {flow }}^{0.71} \alpha^{0.51} H^{-0.34} \\
(R=0.89)
\end{array}
$$

In a similar analysis of individual simple flows active during Etna's 1991-1993 eruption, Calvari \& Pinkerton (1998) showed that

$$
L=10^{3.11}(\mathrm{TADR})^{0.47} \quad\left(R^{2}=0.86\right)
$$

Similar to the Puu Oo case, the correlation was improved if slope and flow emplacement time were included (Fig. 6).

$$
L=10^{1.747} \mathrm{TADR}^{0.43} \alpha^{0.26} t_{\text {flow }}^{0.29} \quad\left(R^{2}=0.94\right)
$$

Additional scatter was induced by variations in yield strength, as well as by volume limitations (flow durations that were too short to allow the full cooling-limited extent to be achieved), and the occasional development of lava tubes that increased the cooling-limited extent. The work by Calvari \& Pinkerton (1998) thus reiterated Walker's (1973) finding that, once consideration extended beyond moderate-duration, channel-fed, cooling-limited, simple flows, the effusion-rate/length relationship no longer held. 


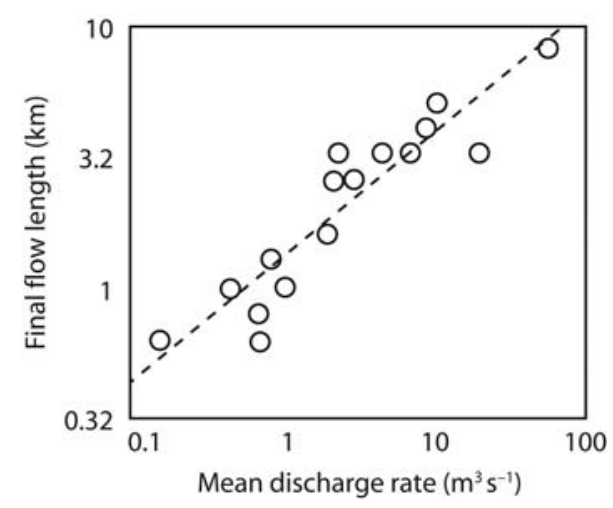

Fig. 6. Figure 6 of Calvari \& Pinkerton (1998) showing the relationship between flow length and time-averaged discharge rates for 17 selected individual aa lava flows at Etna. The best-fit regression between flow length, discharge rate, underlying slope and unit emplacement duration is $L=10^{1.747} \mathrm{TADR}^{0.43} \alpha^{0.26} t_{\text {flow }}{ }^{0.29}$, with an $R^{2}=0.94$

\section{The heat loss link between effusion rate, flow length and flow area}

Walker (1973) suggested that differences in heat loss per unit volume may influence flow emplacement style and dimensions. We next consider the effects of heat loss and thermal insulation on controlling rates of core cooling and, thus, the cooling-limited potential of flow advance. We are able to utilize field measurements and improved thermal models to quantify Walker's (1973) heat-loss/volume parameter, and to show how it varies for different flow characteristics.

Heat is lost from the core of an active flow by conduction through the basal, lateral and surface crusts (e.g. Oppenheimer 1991; Klingelhofer et al. 1999; Quareni et al. 2004). Once at the surface, heat is lost to the atmosphere predominantly by radiation and convection (Dragoni 1989; Crisp \& Baloga 1990; Keszthelyi \& Denlinger 1996; Keszthelyi et al. 2003), and from the base by conduction (Keszthelyi 1995). Cooling causes the thermal, crystallinity and rheological conditions of the flow interior to evolve (e.g. Crisp et al. 1994; Cashman et al. 1999; Griffiths 2000; Lyman et al. 2005) such that additional advance eventually becomes impossible. That is, decreases in the temperature coupled with increases in the crystal content force the viscosity and yield strength upwards to a point where motion is no longer possible. This, in essence, is what 'cooling-limited' means.

For example, using the temperature-viscosity relationship for Etna (alkali basalt) melts given by Giordano \& Dingwell (2003), a decrease in flow core temperature of $200{ }^{\circ} \mathrm{C}$ (from an eruption temperature of $1080{ }^{\circ} \mathrm{C}$, and assuming $0.1 \mathrm{wt} \%$ $\mathrm{H}_{2} \mathrm{O}$ ) will increase viscosity from c. $300 \mathrm{~Pa} \mathrm{~s}$ to $1.5 \times 10^{5} \mathrm{~Pa}$ s. The rhyolite model of Zhang et al. (2003) gives an increase in viscosity from $2.7 \times 10^{7}$ to $1.4 \times 10^{10} \mathrm{~Pa} \mathrm{~s}$ as temperature cools from 900 to $700{ }^{\circ} \mathrm{C}$. In both cases, cooling-induced rheological changes eventually make additional forward motion impossible. This concept underpins all thermo-rheological models designed to simulate cooling-limited flow emplacement (e.g. Danes 1972; Ishihara et al. 1990; Miyamoto \& Sasaki 1997; Harris \& Rowland 2001; Crisci et al. 2004; Vicari et al. 2007).

\section{Gratz number treatments}

Pinkerton \& Sparks (1976) concluded that the influence of cooling on determining flow length could be described using the Gratz Number $(G z)$. This is essentially the ratio between terms that favour lava advancing down slope, namely velocity $(\varpi)$ and flow equivalent diameter $(d)$, and terms that favour heat being lost, namely thermal diffusivity $(\kappa)$ and flow length.

$$
G z=\varpi d^{2} /(\kappa L)
$$

Flow equivalent diameter is defined using channel width $\left(w_{\mathrm{c}}\right)$ and depth $\left(d_{\mathrm{c}}\right)$.

$$
d=2 w_{\mathrm{c}} d_{\mathrm{c}} /\left(w_{\mathrm{c}}+d_{\mathrm{c}}\right)
$$

Assuming cooling-limited behaviour (and constant $\kappa$ ), fast, thick, short flows (high $G z$ ) should be expected to keep moving whereas slow, thin, long flows (low $G z$ ) should be expected to stop.

Thus calculating $G z$ at the point that a flow stopped moving can be used as a test of cooling-limited behaviour. For Etna's 1975 flows, Pinkerton \& Sparks (1976) calculated a $G z$ value of $c .100$ at the distal end. Similarly, $G z$ for Etna's 1983 flows were 230, meaning that they too had probably reached their full, cooling-limited, extents (Guest et al. 1987). Pinkerton \& Wilson (1994) showed how $G z$ could be written in terms of effusion rate, and found that cooling limited flows erupted during the first episodes of the Puu Oo (Kilauea) eruption ceased to advance upon attaining critical $\mathrm{Gz}$ of 280-370. In contrast, Guest et al. (1987) calculated $G z$ of 1500 for Etna's 1981 flow, thus concluding that the flow contained a significant quantity of uncooled lava when it stopped, and hence was volume limited.

Given a critical Gratz number (of approximately 230) that separates cooling-limited from volumelimited behaviour, flow length can thus be plotted as a function of flow velocity and channel equivalent 
diameter (Fig. 7a). This shows quantitatively that the thermo-rheological conditions in faster, higher effusion rate and/or larger channels favour longer flows. But once again, we are essentially re-stating Walker's (1973) proposal that flows fed at higher velocities and/or volume fluxes can advance farther before cooling forces them to halt (Keszthelyi \& Self 1998; Keszthelyi et al. 2000; Harris \& Rowland 2001; Rowland et al. 2004, 2005).

\section{Heat budget approach}

The relationship between flow cooling and length, velocity and/or area can be explored further using the flow's heat budget. Definition of the lava flow heat budget also allows a link to be drawn between surface temperature, degree of thermal insulation and core cooling rate (e.g. Dragoni 1989; Crisp \& Baloga 1990, 1994; Dragoni \& Tallarico 1994; Cashman et al. 1999; Klingelhofer et al. 1999). This in turn allows assessment of the cooling-limited flow length or area as a function of flow velocity (e.g. Keszthelyi \& Self 1998; Keszthelyi et al. 2000) and/or effusion rate (e.g. Pieri \& Baloga 1986; Harris \& Rowland 2001; Rowland et al. 2005; Harris et al. 2007).

There are two approaches that have been used to assess heat loss in flowing lava. One approach follows a control volume down a channel or tube and therefore assesses only the heat loss or gain affecting that particular element of lava at each down-flow step (e.g. Harris \& Rowland 2001). A second approach examines a unit length of channel or tube and assesses the heat flow in and out of that length as lava passes through it (e.g. Crisp \& Baloga 1994; Keszthelyi \& Self 1998). We will limit our discussion here to the second approach.

Assuming that heat lost due to evaporation of falling rain is negligible, the three main heat-loss fluxes (in $\mathrm{W} \mathrm{m}^{-2}$ ) from a unit length of channelized flow are radiation $\left(Q_{\text {rad }}\right)$ and convection $\left(Q_{\text {conv }}\right)$ from the flow surface, and conduction through the channel floor and levees $\left(Q_{\text {cond }}\right)$. These can be written:

$$
\begin{aligned}
Q_{\text {rad }} & =\sigma \varepsilon\left(T_{\text {surf }}{ }^{4}-T_{\text {amb }}{ }^{4}\right) \\
Q_{\text {conv }} & =h_{\mathrm{c}}\left(T_{\text {surf }}-T_{\text {amb }}\right) \\
Q_{\text {cond }} & =-k(\delta T / \delta y)
\end{aligned}
$$

where $\sigma$ is the Stefan-Boltzmann constant $\left(5.67 \times 10^{-8} \mathrm{~W} \mathrm{~m}^{-2} \mathrm{~K}^{-4}\right)$ and $\varepsilon$ is emissivity (c. 0.95), with $h_{\mathrm{c}}$ the convective heat transfer coefficient, and $T_{\text {surf }}$ and $T_{\text {amb }}$ the lava surface and ambient air temperatures, respectively. For an active lava flow, the convective heat transfer coefficient has been measured or calculated at between 10 and $50 \mathrm{~W} \mathrm{~m}^{-2} \mathrm{~K}^{-1}$ (e.g. Keszthelyi et al. 2003; Harris et al. 2005). Thus, to constrain the surface-leaving heat losses, the main variable
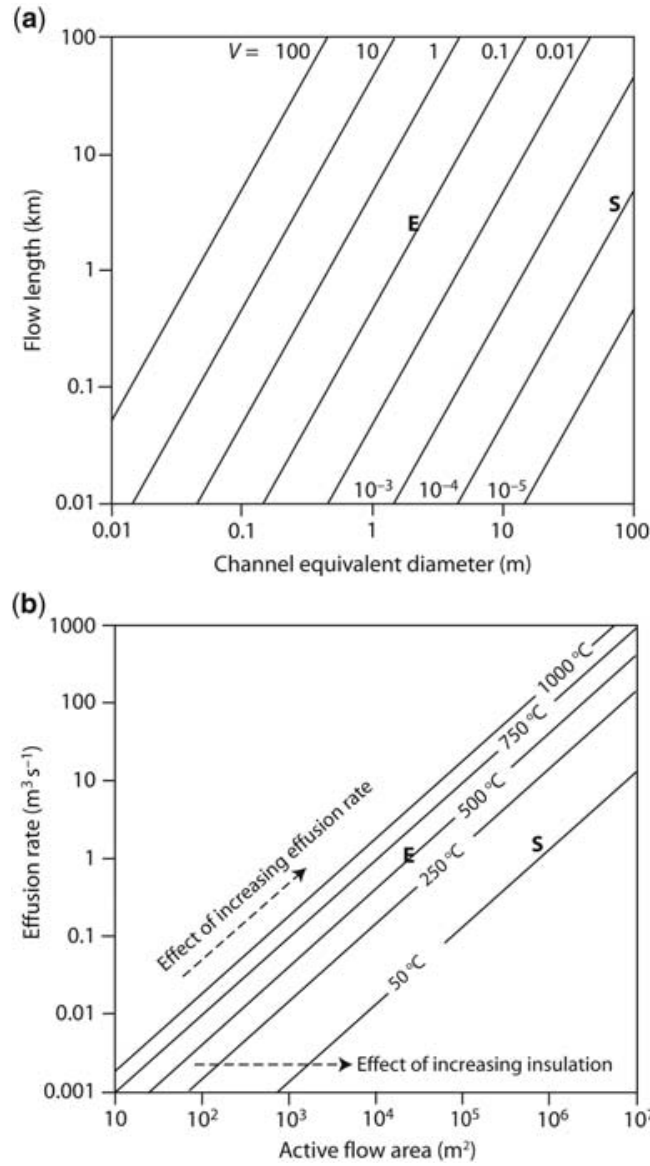

Fig. 7. (a) Gratz number-defined relationship between channel equivalent diameter and flow length for a range of velocities (between $10^{-5}$ and $100 \mathrm{~m} \mathrm{~s}^{-1}$ ) obtained using a critical Gratz number of 230. The locations of the Etna and Santiaguito channels considered here are given by the letters E and S, respectively. (b) Relationship between effusion rate and flow area defined by equation (18) using a range of surface temperatures. The active flow area and effusion rates are given for the May 2001 Etna flow (E) and January 2002 Santiaguito flow (S).

that we need to measure is the surface temperature of the lava. Equation (11) is Fourier's law, in which $k$ is thermal conductivity $\left(c .1 \mathrm{~W} \mathrm{~m}^{-1} \mathrm{~K}^{-1}\right.$ ) and $\delta T / \delta y$ is the temperature gradient over a basal thermal boundary layer of thickness $y$. Equations (9)-(11) give heat fluxes per unit area $\left(\mathrm{W} \mathrm{m}^{-2}\right)$, and should be multiplied by the area over which the surface temperature applies to provide total heat flux in Watts.

The heat fluxes leaving the unit length are countered by two main heat-gain fluxes, these being latent heat of crystallization $\left(Q_{\text {cryst }}\right)$ and heat advected $\left(Q_{\mathrm{adv}}\right)$ into the unit length (i.e. that 
carried by the lava that moves into the unit length). Heat gained by viscous dissipation, $Q_{\text {visc }}$, is negligible. These heat-gain terms can be written:

$$
\begin{aligned}
Q_{\text {cryst }} & =(\delta T / \delta x) \varpi d_{\mathrm{c}} \Lambda(\delta \phi / \delta T) \\
Q_{\mathrm{adv}} & =(\delta T / \delta x) \varpi d_{\mathrm{c}} c_{\mathrm{p}}
\end{aligned}
$$

Here, the main variables are cooling rate per unit distance $(\delta T / \delta x)$, mean flow velocity $(\varpi)$ and channel depth $\left(d_{\mathrm{c}}\right)$, with $\rho, \Lambda, \delta \phi / \delta T$ and $c_{\mathrm{p}}$ being lava density $\left(2600 \mathrm{~kg} \mathrm{~m}^{-3}\right)$, latent heat of crystallization $\left(3.5 \times 10^{5} \mathrm{~J} \mathrm{~kg}^{-1}\right)$, mass fraction of crystallization per degree cooling $(0.02-0.003 \phi / K)$ and specific heat capacity $\left(1230 \mathrm{~J} \mathrm{~kg}^{-1} \mathrm{~K}^{-1}\right)$.

Assuming for simplicity that $Q_{\text {cond }}$ is also negligible, the heat balance can be written:

$$
Q_{\text {cryst }}+Q_{\mathrm{adv}}=Q_{\mathrm{rad}}+Q_{\mathrm{conv}}
$$

or, in full,

$$
\begin{aligned}
& \delta T / \delta x \varpi d \rho\left(\Lambda \delta \phi / \delta T+c_{\mathrm{p}}\right) \\
& \quad=\sigma \varepsilon\left(T_{\text {surf }}{ }^{4}-T_{\mathrm{amb}}{ }^{4}\right)+h_{\mathrm{c}}\left(T_{\text {surf }}-T_{\mathrm{amb}}\right)
\end{aligned}
$$

Solving for core cooling per unit distance $(\delta T / \delta x)$ yields

$$
\delta T / \delta x=\frac{\sigma \varepsilon\left(T_{\text {surf }}^{4}-T_{\text {amb }}^{4}\right)+h_{\mathrm{c}}\left(T_{\text {surf }}-T_{\mathrm{amb}}\right)}{\varpi d_{\mathrm{c}}\left(\Lambda \delta \phi / \delta T+c_{\mathrm{p}}\right)}
$$

and shows that $\delta T / \delta x$ is dependent upon the three main variables already identified, i.e. surface temperature, mean velocity and channel depth. Solving this equation for a range of surface temperatures, velocities and depths reveals that core cooling per distance $(\delta T / \delta x)$ will be reduced at lower surface temperatures (i.e. with increased insulation), higher velocities (i.e. rapid emplacement) or increased flow depths (i.e. protected emplacement whereby the surface area: volume ratio is reduced). The roles of each of these three emplacementfavouring factors are defined and discussed in Keszthelyi \& Self (1998), Keszthelyi et al. (2000) and Harris et al. (2005), with each relationship being plotted here in Figure 8. This shows that, holding all else constant, flows with cooler surface
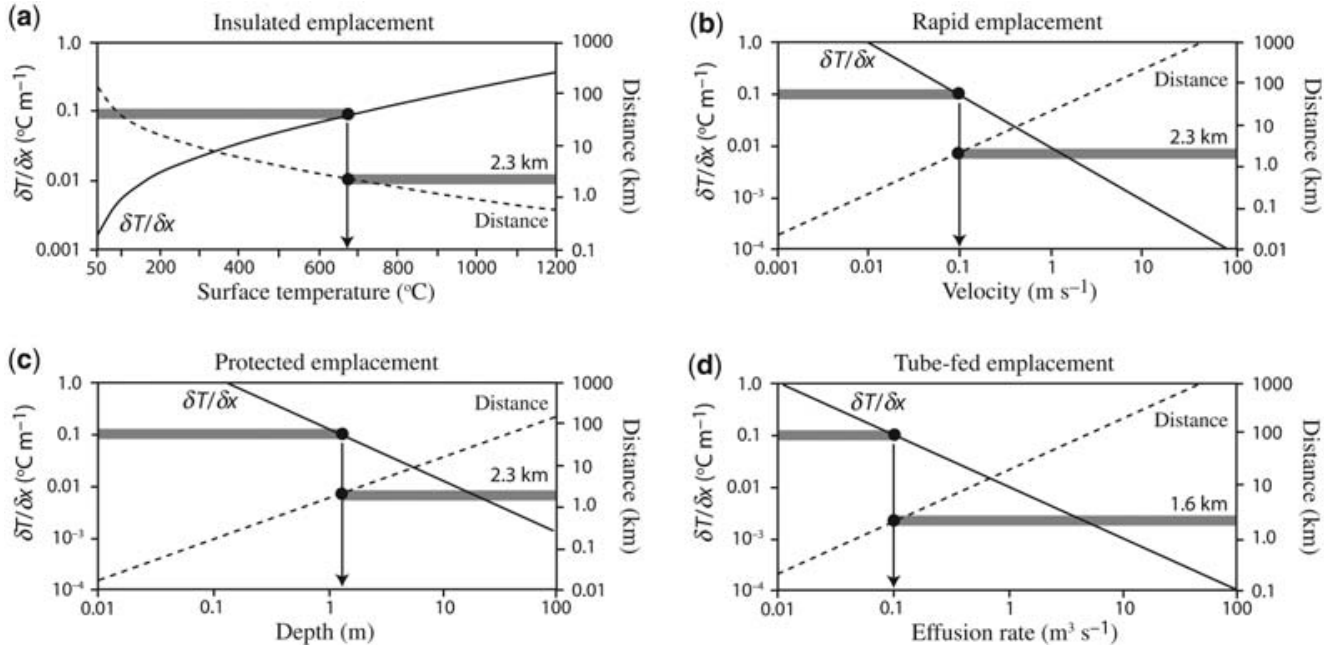

Fig. 8. Cooling per unit distance calculated using equation (15) (solid lines) with cooling-limited lava flow lengths that these give (dashed lines) assuming that flow stops when the eruption temperature has cooled by $200{ }^{\circ} \mathrm{C}$. These are shown for a range of (a) surface temperatures, (b) flow velocities and (c) flow depths. In (a) note that, as surface temperature increases (i.e. insulation becomes poorer), $\delta T / \delta x$ increases, and as a consequence, distance decreases. In (b) and (c) respectively, as velocity and depth increase, $\delta T / \delta x$ decreases, resulting in an increase in distance. In each case we highlight (with balls) the respective field-derived values associated with the May 2001 Etna channel (Bailey et al. 2006; Harris et al. 2005), specifically a surface temperature of $680{ }^{\circ} \mathrm{C}$, velocity of $0.1 \mathrm{~m} \mathrm{~s}^{-1}$, and channel depth of $1.5 \mathrm{~m}$. Note the correspondence of each of these values with a flow distance of $2.3 \mathrm{~km}$ (indicated by grey shading), which compares favourably with an actual flow length of $2.5 \mathrm{~km}$. Results show that the $\delta T / \delta x$ of $c .0 .09^{\circ} \mathrm{C} \mathrm{m}^{-1}\left(90^{\circ} \mathrm{C} \mathrm{km}{ }^{-1}\right)$ was probably typical for this flow. (d) Cooling per unit distance calculated for a tube-fed case using equation (22) for a range of effusion rates. We apply the model to a tube with the same properties as the immature Kilauea example given here. Vertical dashed line in (d) indicates the effusion rate appropriate for the Kilauea tube, which gives a $\delta T / \delta x$ of $0.125^{\circ} \mathrm{C} \mathrm{m}^{-1}\left(125^{\circ} \mathrm{C} \mathrm{km}^{-1}\right)$ to give a cooling-limited length of $c .1 .6 \mathrm{~km}$. 
temperatures (Fig. 8a), higher velocities (Fig. 8b), and/or greater depths (Fig. 8c) all have lower cooling rates, and thus have the potential to extend greater distances before cooling forces them to halt.

These relationships thus allow us to define the heat-loss-driven link between effusion rate and flow length as proposed by Walker (1973). By multiplying equations (9) and (10) by flow area $(A)$, total power (in Watts) lost from the flow due to radiation and convection can be defined as

$$
\begin{aligned}
Q_{\text {rad }} & =A \sigma \varepsilon\left(T_{\text {surf }}{ }^{4}-T_{\text {amb }}{ }^{4}\right) \\
Q_{\text {conv }} & =A h_{\mathrm{c}}\left(T_{\text {surf }}-T_{\text {amb }}\right) \\
Q_{\text {cond }} & =A-k(\delta T / \delta y)
\end{aligned}
$$

The total power flux (in Watts) generated by crystallization and advection can be obtained by multiplying by effusion rate

$$
\begin{aligned}
Q_{\text {cryst }} & =E \rho \Lambda \phi \\
Q_{\mathrm{adv}} & =\Delta T E \rho c_{\mathrm{p}}
\end{aligned}
$$

in which $E$ is effusion rate, $\Delta T$ is total cooling (in Kelvin) from eruption temperature to the point at which the flow stops (Pieri \& Baloga 1986). $\Delta T$ also represents the temperature range over which the maximum crystallinity $(\phi)$ is achieved. This shows that total flow cooling $(\Delta T)$ is directly related to surface temperature, flow area and down-flow crystallization, and inversely related to effusion rate:

$$
\begin{aligned}
\Delta T= & \frac{A\left[\sigma \varepsilon\left(T_{\text {surf }}^{4}-T_{\mathrm{amb}^{4}}\right)+h_{\mathrm{c}}\left(T_{\text {surf }}-T_{\mathrm{amb}}\right)\right]}{E \rho c_{\mathrm{p}}} \\
& -\frac{\Lambda \phi}{c_{\mathrm{p}}}
\end{aligned}
$$

This link between effusion rate and active flow area is the relationship proposed by Baloga \& Pieri (1986), and fully developed in Pieri \& Baloga (1986). Pieri \& Baloga (1986) argue that cooling from an eruption temperature of 1100 $1200{ }^{\circ} \mathrm{C}$ to a solidus of $800-900{ }^{\circ} \mathrm{C}$ is appropriate, to give $\Delta T$ of $200-400{ }^{\circ} \mathrm{C}$. Our field measurements of active flows on Kilauea indicate that after cooling by $c .350{ }^{\circ} \mathrm{C}$ from an eruption temperature of $1150{ }^{\circ} \mathrm{C}$ most lava flows cease to move. $\Delta T$ may, however, be as low as $200{ }^{\circ} \mathrm{C}$ for other cases (Harris et al. 2007). For convenience of illustration we here adopt a value of $200{ }^{\circ} \mathrm{C}$ for the difference between eruption temperature and the core temperature at which flow is no longer possible. We also assume a maximum post eruption crystallization of $45 \%$. These assumptions allow us to plot a direct relationship between effusion rate and flow area for a range of surface temperatures. The relationship shows that as effusion rate and/or thermal insulation increase (i.e. surface temperature decreases), so the potential area that a flow can cover before freezing also increases (Fig. 7b). Pieri \& Baloga (1986) concluded that a correlation between mean output rate and flow planimetric area, modified by case-to-case compositional and temperature differences, can be theoretically (and empirically) shown (Fig. 9). Application of equation (18) for a range of $T_{\text {surf }}$ indicates that the general trend of the mean output rate-area data of Pieri \& Baloga (1986) can be described using a heat-loss driven relationship, with the scatter being due to differing degrees of insulation, as expressed by surface temperature.

Kilburn (2000) linked maximum possible flow length $\left(L_{\max }\right)$ to lava thermal properties and effusion rate using

$$
L_{\max }=[3 \varepsilon S / g \rho \kappa]^{1 / 2} E
$$

Here $\varepsilon S$ is energy per unit volume required for the flow front to exceed its yield strength $\left(2 \times 10^{4} \mathrm{~Pa}\right)$. This is one way to quantify the way in which heat loss (energy released) plays a role in relating effusion rate to lava flow length.
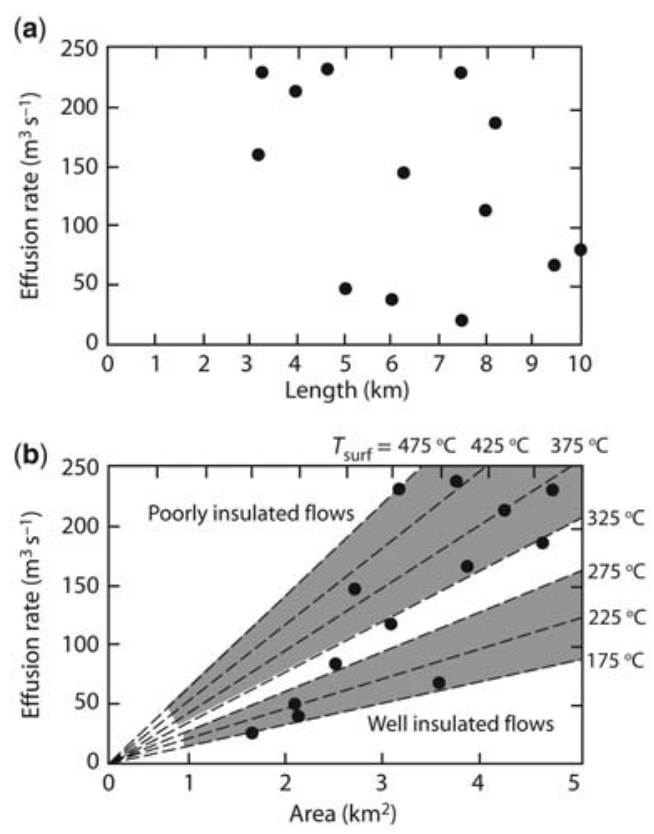

Fig. 9. Figure 3 of Pieri \& Baloga (1986) showing mean effusion rate v. (a) length and (b) area for the 1983-1985 series of eruptions from the Kilauea's Puu Oo vent (Episodes 4, 6, 9, 11, 16, 17, 22, 24, 25, 28, 29, 30 and 31) - all being 'solitary uni-lobate flows' (Pieri \& Baloga 1986), i.e. simple lava flows. In (b) effusion rate v. area relationships, defined using equation (18), for the given range of $T_{\text {surf }}$, are plotted as dashed lines. 
Thus, for any given area or length, more poorly insulated flows (flows with higher surface temperatures) require higher effusion rates to attain the same area or length as well-insulted flows (Fig. 9b). This, in essence, supports the limitation of the Walker (1973) relationship to a specific set of flow emplacement conditions. Namely, tube-fed and channel-fed flows cannot be considered together (Pinkerton \& Wilson 1994).

\section{Thermal insulation, heat loss and flow length}

Heat loss from a flow surface thus plays a fundamental role in determining core-cooling rates, thereby influencing cooling-limited flow extension. Insulation is what controls the amount of heat passing from the flow core to the flow surface, thus it is the most fundamental factor that controls core cooling rates. We can classify four types of flow in terms of insulation and efficiency of heat loss:

1. Channel-fed (poorly crusted) flow

2. Poorly-developed (immature) tube-fed flow

3. Mature master-tube-fed flow

4. Well-insulated (heavily crusted) flow

Equation (18) can be re-written to solve for area:

$$
A=\frac{E\left[\rho\left(\Lambda \phi+\Delta T c_{\mathrm{p}}\right)\right]}{\sigma \varepsilon\left(T_{\mathrm{surf}}{ }^{4}-T_{\mathrm{amb}}{ }^{4}\right)+h_{\mathrm{c}}\left(T_{\text {surf }}-T_{\mathrm{amb}}\right)}
$$

and shows that, if effusion rate is constant but insulation gets better (i.e. the difference between $T_{\text {surf }}$ and $T_{\mathrm{amb}}$ gets smaller), the result is an increased area over which a flow can extend (Fig. 7b). We next use four case studies from Etna (poorly crusted), Kilauea (immature tube), Santiaguito (heavily crusted) and one set of previously documented flows at Kilauea (master tubes) to illustrate the typical surface temperatures, heat losses and, hence, cooling rates and cooling-limited low lengths associated with each case. We include the Kilauea immature tube case because there has already been considerable attention given to low cooling rates experienced by lava flowing in large, mature master tubes (e.g. Swanson 1973; Keszthelyi 1995; Sakimoto \& Zuber 1998; Clague et al. 1999; Helz et al. 2003; Witter \& Harris 2007). Inclusion of this immature tube case shows that not all tube-fed lava is as well insulated as that flowing in a master tube.

\section{Channel-fed (poorly crusted) flow}

An open channel with a poorly developed surface crust has poor surface insulation and high surface temperatures (e.g. Flynn \& Mouginis-Mark 1992). As with all flows, the source of heat to maintain the high surface temperature is the flow core, thus high heat losses reflect high rates of core cooling. Thus at a given effusion rate, channel-fed flow will be associated with short cooling-limited flow areas and lengths (Fig. 7b). Next we show how the Gratz number and cooling rate per distance approaches produce complementary results, relating flow dimensions, effusion rates and heat losses.

Bailey et al. (2006) document activity along the proximal section of a $3 \mathrm{~m}$ wide, $1.5 \mathrm{~m}$ deep, channel that was active on Mount Etna during May 2001. This channel fed a simple aa flow which extended c. $2.5 \mathrm{~km}$ from the vent. Although punctuated by relatively short periods of more vigorous surging flow, when surface velocities peaked at $0.21 \mathrm{~m} \mathrm{~s}^{-1}$, typical velocities were $c .0 .1 \mathrm{~m} \mathrm{~s}^{-1}$ to give an effusion rate of $c .0 .45 \mathrm{~m}^{3} \mathrm{~s}^{-1}$. The surface of the channel was characterized by a thin, plastic crust, which occupied c. $97 \%$ of the surface area, broken by cracks that exposed molten lava (Harris et al. 2005). Maximum surface temperatures for this channel gave $733-1042{ }^{\circ} \mathrm{C}$ for cracks, and $658-877^{\circ} \mathrm{C}$ for the crust (Bailey et al. 2006). These compared with a thermocouple-measured core temperature of $1065^{\circ} \mathrm{C}$. Thermal measurements integrated across the entire width of the channel revealed surface temperatures in the range of $220-980{ }^{\circ} \mathrm{C}$, with a mean of $680{ }^{\circ} \mathrm{C}$ (Harris et al. 2005).

Using the channel dimensions and typical velocity noted above, and a critical Gratz Number of 230 , equation (7) gives a flow length of $c .2 .5 \mathrm{~km}$ (Fig. 7b), which is a length identical to that observed. This Gratz number approximates the critical value of $c .100$ calculated by Pinkerton \& Sparks (1976) for Etna flows, and matches that of $230 \mathrm{cal}-$ culated for Etna's cooling-limited 1983 flow (Guest et al. 1987), suggesting that the May 2001 flow was approaching, or at, its cooling limited extent.

Given the integrated surface temperature of $680{ }^{\circ} \mathrm{C}$, we obtain radiative and convective heat fluxes of 4.4 and $3.3 \times 10^{4} \mathrm{~W} \mathrm{~m}^{-2}$, respectively. Using these values plus the measured channel dimensions and average surface velocity in equation (15), we obtain a core cooling rate of $9 \times 10^{-3}{ }^{\circ} \mathrm{C} \mathrm{s}^{-1}$, which converts to $c .90{ }^{\circ} \mathrm{C} \mathrm{km}^{-1}$ (Harris et al. 2005). If the flow stops once it has cooled by $200{ }^{\circ} \mathrm{C}$, then this gives a cooling limited length of $2.3 \mathrm{~km}$ (Fig. 8), essentially identical to the Gratz number-derived length noted above. In reality, the high heat fluxes apply only to the proximal section of the flow. Down flow, increasingly mature crusts mean that surface temperatures, and hence heat fluxes and cooling rates both decline with distance. An extensive, thick, cool and stable carapace of aa clinker in medial-to-distal sections 
may decrease cooling rates to $5-20{ }^{\circ} \mathrm{C} \mathrm{km}^{-1}$ across such sections (Harris et al. 2007). This is consistent with the equation (18) prediction where, given an active flow area of $2.3 \times 10^{4} \mathrm{~m}^{2}$ fed at an effusion rate of $0.45 \mathrm{~m}^{3} \mathrm{~s}^{-1}$, the data point fits on the heat loss defined effusion rate-area relationship (Fig. 7) obtained using a surface temperature of $500{ }^{\circ} \mathrm{C}$ rather than $680{ }^{\circ} \mathrm{C}$. The lower temperature implies that some of the flow surface in the medial and distal sections had temperatures lower than those recorded at the proximal channel.

The heat-loss-based equations linking effusion rate and length appear to produce a good fit to this poorly insulated Etna channel case (Fig. 8a). The main way that this flow could have lengthened or increased in area under these thermal conditions would have been for the effusion rate to have been higher (Fig. 8b) and/or for the flow equivalent diameter to have been greater (Fig. 8c). Alternatively, holding effusion rate and equivalent diameter constant, an increase in flow length would have required a more insulating surface (Fig. 8a).

\section{Immature tube-fed flow}

In many basaltic cases, master lava tubes represent the most thermally efficient mode of flow emplacement, with the tube roof limiting heat losses and thus core cooling rates. Here, instead, we examine a poorly developed, small tube because these have been somewhat overlooked in previous treatments of heat loss from active pahoehoe flow fields, even though they are much more representative of the advancing front of an active pahoehoe flow.

Keszthelyi (1995) provides a thermal model that allows calculation of cooling rates for lava flowing in tubes using appropriate field measurements. Here we use a simplified version of the Keszthelyi (1995) model, where we assume that there are no skylights in the tube (hence there is no heat loss by direct radiation to the sky) and no heat loss to air flowing in the tube headspace, i.e. the empty space between the lava stream within the tube and the tube roof (Fig. 10).

Cooling per unit distance can now be calculated using the three main heat fluxes (per unit distance, that is, $\mathrm{W} \mathrm{m}^{-1}$ ) for a tube. Following Keszthelyi (1995), these are conduction of heat across the roof rock ( $\left.Q_{\text {roof }}\right)$, convection by air circulating in fractures around the tube $\left(Q_{\text {circ }}\right)$, and boiling of rain water seeping into the surrounding rocks $\left(Q_{\text {rain }}\right)$. We calculate $Q_{\text {roof }}$ using the roof thickness $\left(h_{\text {roof }}\right)$ in Fourier's law.

$$
Q_{\text {roof }}=-k\left(\Delta T / h_{\text {roof }}\right) W_{\text {tube }}
$$

In which $\Delta T$ is the temperature difference between the flowing lava and the ground surface above the tube $\left(c .1100{ }^{\circ} \mathrm{C}\right)$ and $W_{\text {tube }}$ is tube width. $Q_{\text {circ }}$ can be calculated using $h_{\mathrm{c}}$ of $10 \mathrm{~W} \mathrm{~m}^{-2} \mathrm{~K}^{-1}$ in an adapted version of equation (10), i.e. $Q_{\text {circ }}=h_{\mathrm{c}}$ $\Delta T W_{\text {tube }}$. This heat transfer coefficient is calculated for free convection following Harris et al. (2005) using values for air at $575^{\circ} \mathrm{C}$ from Holman (1992) and a boundary layer thickness equal to the thickness of the tube roof $(c .2 .5 \mathrm{~m})$. Finally, $Q_{\text {rain }}$ is obtained, following Keszthelyi (1995), from

$$
Q_{\text {rain }}=\delta R / \delta t D_{100} \rho_{\mathrm{H}_{2} \mathrm{O}} \Lambda_{\mathrm{H}_{2} \mathrm{O}}
$$

where $\delta R / \delta t$ is rainfall rate, $D_{100}$ is diameter of the $100{ }^{\circ} \mathrm{C}$ isotherm, $\rho_{\mathrm{H}_{2} \mathrm{O}}$ is density of water (1020 $\mathrm{kg} \mathrm{m}^{-3}$ ) and $\Lambda_{\mathrm{H}_{2} \mathrm{O}}$ is latent heat of vaporization of water plus heat needed to bring water to boiling point $\left(c .2 .8 \mathrm{MJ} \mathrm{kg}^{-1}\right)$. We use $\delta R / \delta t$ of c. $8 \times 10^{-8} \mathrm{~m} \mathrm{~s}^{-1}$ for Kilauea (Keszthelyi 1995 ), and set $D_{100}$ to the width of the flow unit within which the tube is centred. Now, adapting equation (14):

$$
\begin{aligned}
\delta T / \delta x= & \left(Q_{\text {roof }}+Q_{\text {circ }}\right. \\
& \left.+Q_{\text {rain }}\right) /\left[E \rho\left(\Lambda \delta \phi / \delta T+c_{\mathrm{p}}\right)\right]
\end{aligned}
$$

The tube we consider here was produced during the Mauna Ulu eruption of Kilauea (1969-1974), and is exposed along the Chain of Craters Road in Hawaii Volcanoes National Park (Fig. 10). The tube formed within a $c .50 \mathrm{~m}$ wide channel, bounded by aa levees. The channel was then in filled with pahoehoe, with the $4.2 \mathrm{~m}$ wide tube developing roughly centrally in the channel. The final flow within the tube comprised a $c .2 .3 \mathrm{~m}$ wide stream on the right-bank side of the tube (facing downstream), with a depth of 0.04-0.50 m (Fig. 10). Above the flow surface, the headspace was $0.25-0.8 \mathrm{~m}$ high $($ mean $=0.65 \mathrm{~m})$. The tube walls display lobes of melted wall material that flowed down the wall, and the roof displays conical stalactites, a form consistent with roof melting and dripping (Calvari \& Pinkerton 1999). These melt features support the assumption that the air in the tube was at approximately the same temperature as the lava so that there was essentially no cooling due to convection of the air overlying the stream in the tube. The tube roof comprises a pile of three or four pahoehoe units with a total thickness of c. $2.5 \mathrm{~m}$ (Fig. 10).

We use the mean flow depth $(0.21 \mathrm{~m})$ and slope $\left(8^{\circ}\right)$ in the Jeffreys Equation (Jeffreys 1925) to obtain a mean velocity $\left(\varpi_{\text {mean }}\right)$ from

$$
\varpi_{\text {mean }}=\rho g \sin (\alpha) d^{2} / n \eta
$$

in which $n$ is a constant dependant on channel width, with a value of 3 suggested by Booth \& Self (1973) for channels that are wide relative to their depth, and $\eta$ is viscosity. Using a viscosity of 

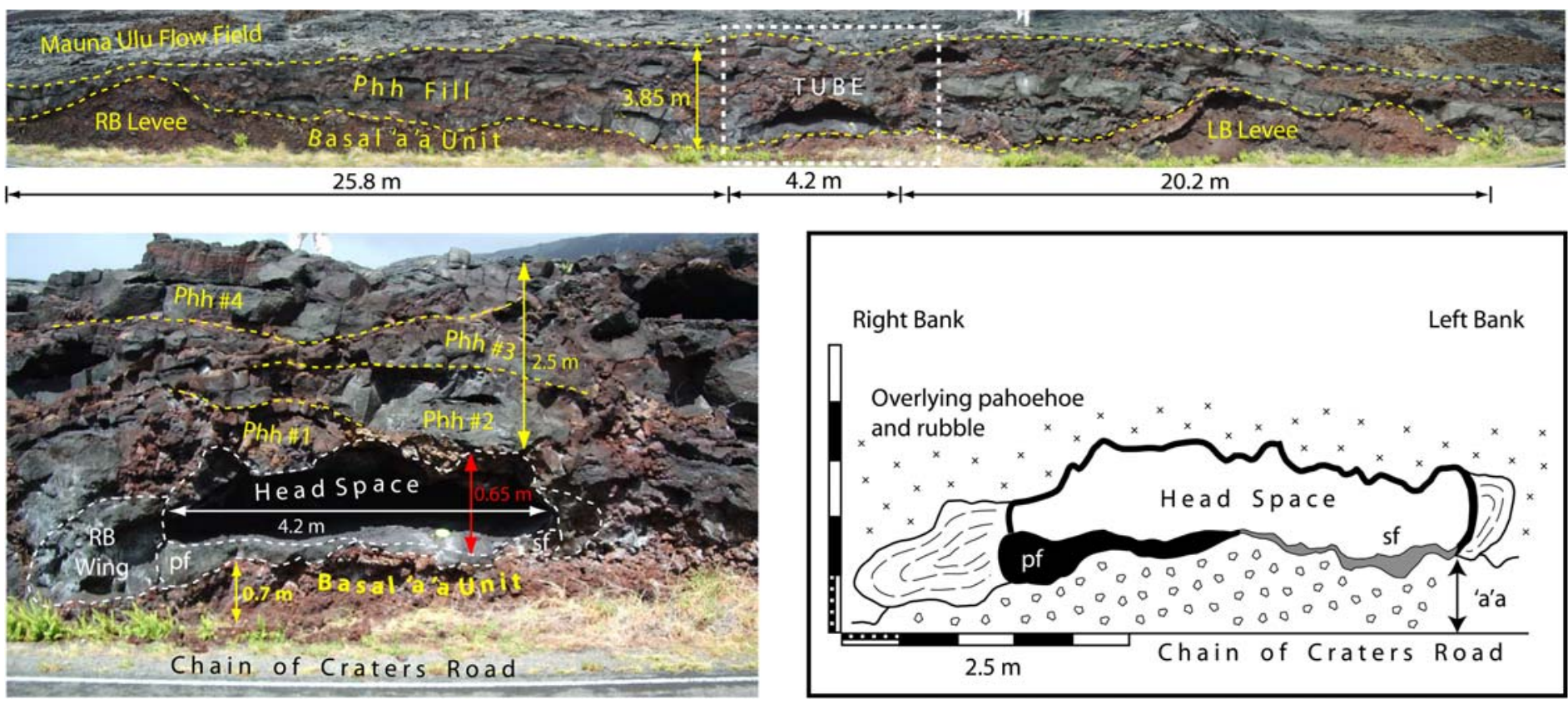

Fig. 10. Road-cut section in the Chain of Craters road showing a $50 \mathrm{~m}$ wide leveed aa flow, infilled with pahoehoe ( $R B=$ right bank, $L B=$ left bank). A tube (outlined in white box) is centred in this unit, and is shown larger in the lower panels. It is overlain by between 3 and 4 pahoehoe units (phh 1-4). A c. $1.4 \mathrm{~m}$ wide plug of lava completely fills the tube at the right bank (RB wing). Following Keszthelyi \& Self (1998), this is interpreted to be tube fill resulting from gradual freezing of the lava from the tube edge inwards. A similar (c. $0.3 \mathrm{~m}$ wide) structure is apparent at the left bank. The tube is lined with a smooth, light grey, coating with conical roof stalactites and dribble structures flowing down the walls. The tube contains two streams, a $2.3 \mathrm{~m}$-wide primary and a $1.8 \mathrm{~m}$-wide secondary stream on the right and left bank sides of the tube, respectively (pf and sf). Stream sf shows a sense to flow that diverges from stream pf, and appears to have stagnated to form a left bank levee for the primary stream. The primary stream comprises a $1.2 \mathrm{~m}$-wide central plug of ropey pahoehoe (ropes point down-flow) surrounded by right and left bank shear zones of frozen, embryonic aa. These are 0.7 and $0.4 \mathrm{~m}$ wide, respectively. Lava has fingered downwards from the base of the two flows into the underlying aa clinker to form cow-udder-like intrusions of pahoehoe into the clinker. 
200-400 Pas for Hawaiian lavas (Macdonald 1963) we obtain a velocity of $c .0 .2 \mathrm{~m} \mathrm{~s}^{-1}$. Given the flow cross-sectional area $\left(0.45 \mathrm{~m}^{2}\right)$, this results in an effusion rate of $0.08 \mathrm{~m}^{3} \mathrm{~s}^{-1}$. Using these values in equations (20) to (22) we obtain a cooling rate of $c .2 \times 10^{-2}{ }^{\circ} \mathrm{C} \mathrm{s}^{-1}$ which, at these velocities, converts to $c .125^{\circ} \mathrm{C} \mathrm{km}^{-1}$. We now arrive (using a total cooling value $200{ }^{\circ} \mathrm{C}$ ) at a cooling limited distance of $c .1 .6 \mathrm{~km}$ for lava flowing in this tube, in spite of very low $\left(<0.1 \mathrm{~m}^{3} \mathrm{~s}^{-1}\right)$ effusion rates and a shallow $(<0.25 \mathrm{~m})$ depth of the flowing lava. As noted above, the tube considered here was not a master tube, but was selected to indicate the maximum likely cooling rates associated with small tubes fed at relatively low effusion rates. This heat loss is applicable to the "complex, anastomosing system' (Peterson et al. 1994) of poorly developed small tubes forming at the active front of an advancing tube-fed pahoehoe flow field.

\section{Master tube-fed flow}

Higher effusion rates, tube dimensions and roof thicknesses in master tubes (e.g. Kauahikaua et al. 1998) can decease cooling rates to $c .1^{\circ} \mathrm{C} \mathrm{km}^{-1}$, and Swanson (1973) reported this same heat losses value for master tubes in the early part of the Mauna Ulu eruption. Cooling rates obtained from heat loss models applied to master tubes active during Kilauea's Puu Oo-Kupaianaha eruption give $0.4-1.2{ }^{\circ} \mathrm{C} \mathrm{km}^{-1}$ (Keszthelyi 1995; Sakimoto $\&$ Zuber 1998) during a time when typical timeaveraged discharge rates have been $c .4 \mathrm{~m}^{3} \mathrm{~s}^{-1}$ (Sutton et al. 2003). These agree with the $c$. $0.6{ }^{\circ} \mathrm{C} \mathrm{km}^{-1}$ value along a $12 \mathrm{~km}$ tube length based on olivine geothermometer measurements (Helz et al. 2003). Based on a decrease in $\mathrm{MgO}$ from $c .6 .8$ to $c .6 .2 \mathrm{wt} \%$ over a distance of $40 \mathrm{~km}$ in Kilauea's AD 1445 Ailaau flow field, Clague et al. (1999) obtained an even lower value of $0.35{ }^{\circ} \mathrm{C} \mathrm{km}^{-1}$. The presence of skylights in a tube roof will increase cooling per unit distance. Data of Witter \& Harris (2007) give a maximum cooling rate of $8{ }^{\circ} \mathrm{C} \mathrm{km}^{-1}$ for a tube with a roof that is $50 \%$ skylights. Nevertheless, these low cooling rates increase the potential cooling-limited distances for low effusion rate $\left(<5 \mathrm{~m}^{3} \mathrm{~s}^{-1}\right)$ tube-fed flows to tens, and perhaps hundreds, of kilometres. This reinforces the argument of Pinkerton \& Wilson (1994) that tube- and channel-fed flow cannot be considered together in any effusion rate-flow length relationships.

\section{Well-insulated (heavily crusted) flow}

By reducing heat fluxes, and hence core cooling rates increased insulation can allow even high-viscosity dacite lava flows to extend farther than might be expected based on their rheology. Silicic (c. $62 \mathrm{wt} \% \mathrm{SiO}_{2}$ ) flows observed at Santiaguito (Guatemala) are characterized by complete coverings of extremely cool surface crusts allowing excellent insulation (Harris et al. 2002, 2004). Effective insulation reduces surface temperatures to $50-70{ }^{\circ} \mathrm{C}$, and radiative and convective heat fluxes to 0.02 and $0.18 \times 10^{4} \mathrm{~W} \mathrm{~m}^{-2}$, respectively. These high viscosity $\left(10^{9}-10^{10} \mathrm{~Pa} \mathrm{~s}\right)$ flows, however, have significantly greater thicknesses $(c$. $40 \mathrm{~m})$ and lower velocities $\left(c .1 .4 \times 10^{-4} \mathrm{~m} \mathrm{~s}^{-1}\right)$ than the basaltic cases considered above. When used in equation (15) the Santiaguito values give a cooling rate of only $8.4 \times 10^{-5}{ }^{\circ} \mathrm{C} \mathrm{s}^{-1}$. The low flow velocity converts this to $60^{\circ} \mathrm{C} \mathrm{km}^{-1}$, a value slightly lower than that of the May 2001 Etna channel. This results in a calculated cooling-limited length of $c .3 .3 \mathrm{~km}$ for the Santiaguio flow, consistent with field observations (Harris et al. 2004).

This is also consistent with the Gratz number based calculation where a critical Gratz number of 230 combined with a typical width of $180 \mathrm{~m}$ (Harris et al. 2004), gives a cooling-limited length of $3.7 \mathrm{~km}$ (Fig. 7a). The observed maximum length for this flow was $3.75 \mathrm{~km}$. Given an active area of $67.5 \times 10^{4} \mathrm{~m}^{2}$ fed at an effusion rate of $1.61 \mathrm{~m}^{3} \mathrm{~s}^{-1}$ (Harris et al. 2004), and using equation (18), the data point falls on the heat loss defined effusion rate-area relationship associated with a surface temperature of $c .70^{\circ} \mathrm{C}$ (Fig. 7b).

Again, the heat loss based equations linking effusion rate, length and area produces a good fit to the field data. In this case, extremely effective thermal insulation minimizes heat losses to allow this flow to extend a reasonable distance before cooling forces stagnation, in spite of extremely low advance velocities. This conclusion is in agreement with Manley (1992), who stated that 'a common misconception about rhyolite lava flows is that they cannot advance far from their vents and are considered to be small due to their high viscosities'. Manley's (1992) model-based results and field studies also show that slow cooling of 100-300 m thick units mean that such flows may actually remain active for decades, although advancing at extremely low velocities.

As in the poorly insulated 2001 Etna case, if we use a model that takes into account the correct (in this case well-insulated) thermal state of the flow, a relationship between effusion rate and flow length and/or area can be obtained. The main way to increase the flow length and/or area for these thermal conditions remains to increase flow depth, flow equivalent diameter or effusion rate (Fig. 7). Alternatively, to increase the active area at the same effusion rate would require improved insulation (Fig. 7b) which, in the Santiaguito case, 
would be difficult given that surface crusts on these active flows have already cooled to near-ambient temperatures.

\section{Rapid and insulated emplacement}

To sum up, for any given cooling per unit time, the potential length a flow can extend will increase with velocity (Fig. 11). Velocity may, in turn, be tied to viscosity, slope and/or flow depth. Thus, the low cooling rates of the Santiaguito flows are countered by their extremely low velocities, thereby reducing their potential length. If flows with the Santiaguito cooling rates were emplaced at higher velocities, then they would have the potential to extend great distances (Fig. 11). Conversely, if lava in a typical Etna channel were emplaced at the Santiaguito velocities, then it would advance only a very short distance (Fig. 11). This is essentially the conclusion of Keszthelyi \& Self (1998) where, for a flow to extend a great distance, it either needs to be emplaced at a high velocity and/or be well insulated.

\section{Heat lost per unit volume}

As Walker (1973) surmised, what really counts is the heat lost per unit volume of lava (i.e. cooling rate divided by effusion rate). If we take the cases considered above we obtain the following.

(1) Etna channel:

$$
\begin{aligned}
& E=0.45 \mathrm{~m}^{3} \mathrm{~s}^{-1}, \quad \delta T / \delta t=9 \times 10^{-3}{ }^{\circ} \mathrm{C} \mathrm{s}^{-1}, \\
& \delta T / \delta V=2 \times 10^{-2}{ }^{\circ} \mathrm{C} \mathrm{m}^{-3}
\end{aligned}
$$

(2) Mauna Ulu tube:

$$
\begin{aligned}
& E=0.08 \mathrm{~m}^{3} \mathrm{~s}^{-1}, \quad \delta T / \delta t=2 \times 10^{-2}{ }^{\circ} \mathrm{C} \mathrm{s}^{-1}, \\
& \delta T / \delta V=2.5 \times 10^{-1}{ }^{\circ} \mathrm{C} \mathrm{m}^{-3}
\end{aligned}
$$

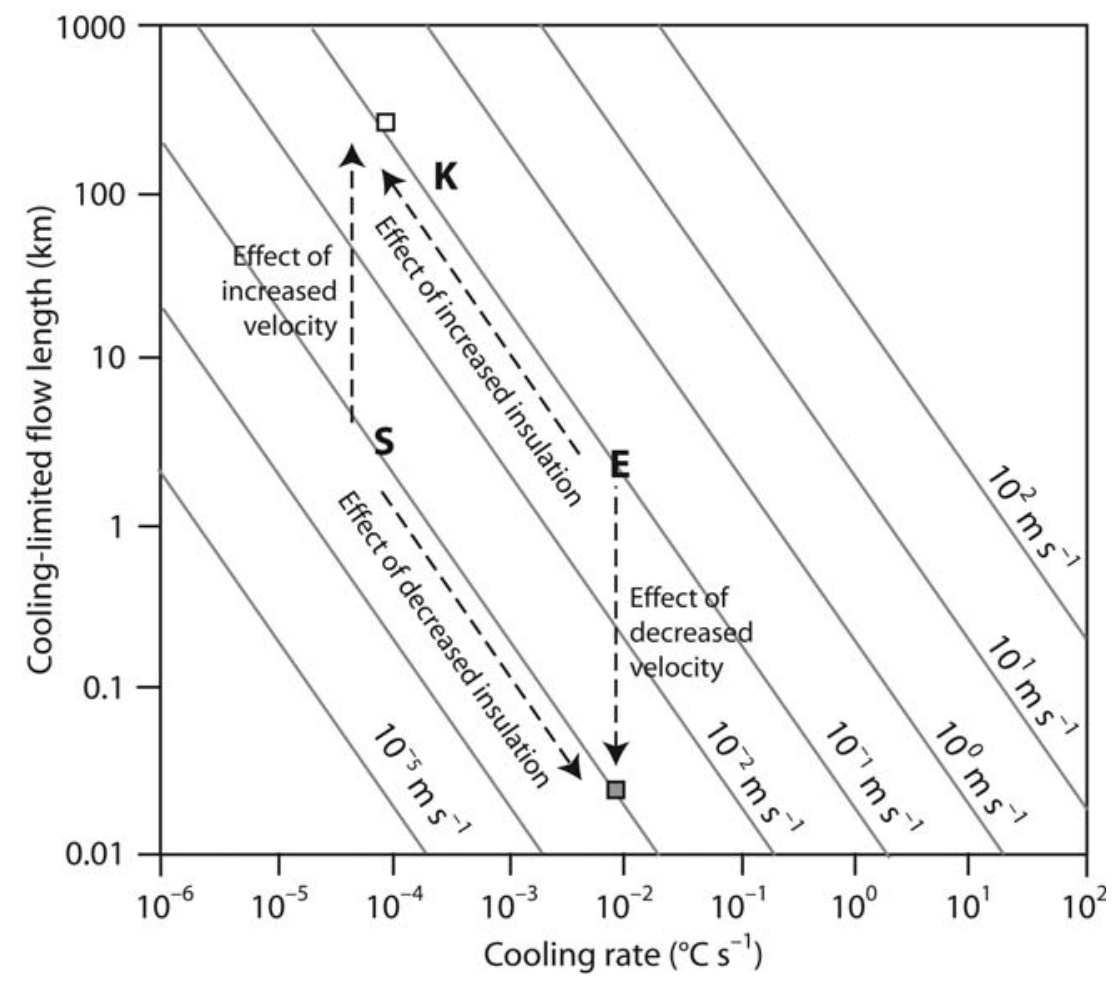

Fig. 11. Relationship between cooling-limited flow length and cooling rate for a range of given velocities. The letters E, $\mathrm{S}$ and K respectively give the Etna (poorly insulated), Santiaguito (well-insulated) and Kilauea (tube-fed) combinations of flow length, cooling rate and velocity. The white square marks a hypothetical flow length that would be obtained if (i) the Etnean flow had the same velocity, but the well-insulated cooling properties of the Santiaguito flow, or (ii) the Santiaguito flow had a the same cooling properties but the velocity of the Etna flow. The grey square marks a hypothetical flow length that would be obtained if (iii) the Etnean flow had the same cooling properties, but low velocity of the Santiaguito flow, or (iv) the Santiaguito flow had a the same velocity, but the poorly insulated properties of the Etna flow. 
(3) Master tube:

$$
\begin{aligned}
& E=4.0 \mathrm{~m}^{3} \mathrm{~s}^{-1}, \quad \delta T / \delta t=1 \times 10^{-3}{ }^{\circ} \mathrm{C} \mathrm{s}^{-1}, \\
& \delta T / \delta V=3 \times 10^{-4}{ }^{\circ} \mathrm{C} \mathrm{m}^{-3}
\end{aligned}
$$

(4) Santiaguito:

$$
\begin{aligned}
& E=1.61 \mathrm{~m}^{3} \mathrm{~s}^{-1}, \quad \delta T / \delta t=8.4 \times 10^{-5}{ }^{\circ} \mathrm{C} \mathrm{s}^{-1}, \\
& \delta T / \delta V=5 \times 10^{-4}{ }^{\circ} \mathrm{C} \mathrm{m}^{-3} .
\end{aligned}
$$

With this fundamental control we can show that the master tube and heavily crusted dacite flow are the most thermally efficient means of transporting lava. Immature tubes and open channels are twoto-three orders of magnitude less efficient.

\section{Conclusion}

To place ourselves back in the context of Walker's (1973) work, flow lengths can be related to effusion rate through heat loss. Given a greater volume flux, the heat supplied to the flow is increased and thus so too is the cooling-limited extent. Viscosity and slope can also influence flow length, with lower viscosities and steeper slopes promoting longer but thinner flows. This adds scatter to a simple effusion rate v. length relationship. In addition, if we begin to consider compound flow fields of increasing emplacement duration, the direct relationship between flow field length and effusion rates becomes further complicated. Topography also plays a role in that if the flow becomes trapped in a depression (such as a pit crater), then advance will be impeded (Walker 1973).

In the case of a short-duration, simple lava flow the main complicating factors are volume limits and insulation. Addition of a cool, thick, insulating crust or tube roof reduces cooling rates and thereby allows a flow to extend significantly greater distances than in un-roofed, channelized cases. This means, following Pinkerton \& Wilson (1994), that tubes, insulated flows and channels must be considered separately in any length v. effusion rate correlation. In addition, volume-limited flows will not attain their full cooling-limits (e.g. Swanson 1973). Thus flows of limited duration must be removed from the consideration. This was the original premise of Walker (1973) who, by omitting flows of durations $<30 \mathrm{~h}$, reduced the bias caused by short-lived, volume-limited eruptions.

Our review illustrates the original hypothesis of Walker (1973): flow length is controlled largely by differences in the rate of heat loss per unit volume or per distance travelled, which in turn vary with effusion rate. Thus for channel-fed, cooling-limited, simple-flow cases effusion rates should be directly related to the cooling-limited length. The same should apply when insulated and tube-contained cases are subjected to the same analysis.

The outcrop measurements at the Chain of Craters lava tube are courtesy of the students in the University of Hawaii GG605 (Lava Flow Rheology and Morphology) class, Autumn 2005: R. Carey, C. Hamilton, P. Jennings, J. Marske, M. Rotella, W. Stovall and M. Klawonn. A. Gurioli and D. Gurioli are also thanked for help with the initial mapping. Critical reviews of this manuscript by J. Kauahikaua and J. Dehn produced considerable improvement. This is SOEST contribution no. 7753.

\section{References}

Bailey, J. E., Harris, A. J. L., Dehn, J., Calvari, S. \& Rowland, S. K. 2006. The changing morphology of an open lava channel on Mt. Etna, Bulletin of Volcanology, 68, 497-515.

B ALOGA, S. \& PIERI, D. 1986. Time-dependent profiles of lava flows. Journal of Geophysical Research, 91, 9543-9552.

BeHnCKe, B. \& Neri, M. 2003. The July-August 2001 eruption of Mt. Etna (Sicily). Bulletin of Volcanology, 65, $461-476$.

Booth, B. \& SELF, S. 1973. Rheological features of the 1971 Mount Etna lavas. Philosophical Transactions of the Royal Society London, 274, 99-106.

CAlvari, S. \& Pinkerton, H. 1998. Formation of lava tubes and extensive flow field during the 1991-1993 eruption of Mount Etna. Journal of Geophysical Research, B103, 27291-27301.

Calvari, S. \& Pinkerton, H. 1999. Lava tube morphology on Etna and evidence for lava flow emplacement mechanisms. Journal of Volcanological and Geothermal Research, 90, 263-280.

Cashman, K. V., Thornber, C. \& Kauahikaua, J. P. 1999. Cooling and crystallization of lava in open channels, and the transition of pahoehoe to aa. Bulletin of Volcanology, 61, 306-323.

Clague, D. A., Hagstrum, J. T., Champion, D. E. \& BeEson, M. H. 1999. Kilauea summit overflows: their ages and distribution in the Puna district, Hawaii. Bulletin of Volcanology, 61, 363-381.

Crisci, G. M., Rongo, R., Di Gregorio, S. \& SPATARO, W. 2004. The simulation model SCIARA: the 1991 and 2001 lava flows at Mount Etna. Journal of Volcanology and Geothermal Research, 132, 253-267.

CRisp, J. \& BAlogA, S. 1990. A method for estimating eruption rates of planetary lava flows. Icarus, $\mathbf{8 5}$, 512-515.

CRISP, J. \& BALOGA, S. 1994. Influence of crystallization and entrainment of cooler material on the emplacement of basaltic aa lava flows. Journal of Geophysical Research, 99, 11,819-11,831.

Crisp, J., Cashman, K. V., Bonini, J. A., Hougen, S. B. \& PIERI, D. C. 1994. Crystallization history of the 1984 Mauna Loa lava flow. Journal of Geophysical Research, B99, 7177-7198.

DANES, Z. F. 1972. Dynamics of lava flows. Journal of Geophysical Research, 77, 1430-1432. 
Dragoni, M. 1989. A dynamical model of lava flows cooling by radiation. Bulletin of Volcanology, 51, $88-95$.

Dragoni, M. \& Tallarico, A. 1994. The effect of crystallization on the rheology and dynamics of lava flows. Journal of Volcanological and Geothermal Research, 59, 241-252.

Flynn, L. P. \& Mouginis-Mark, P. J. 1994. Temperature of an active lava channel from spectral measurements, Kilauea Volcano, Hawaii. Bulletin Volcanology, 56, 297-301.

Frazzetta, G. \& Romano, R. 1984. The 1983 Etna eruption: event chronology and morphological evolution of the lava flow. Bulletin of Volcanology, 47, 1079-1096.

Giordano, D. \& Dingwell, D. B. 2003. Viscosity of hydrous Etna basalt: implications for Plinian-style basaltic eruptions. Bulletin of Volcanology, 65, 8-14.

Guest, J. E., Kilburn, C. R. J., Pinkerton, H. \& Duncan, A. M. 1987. The evolution of lava flowfields: observations of the 1981 and 1983 eruptions of Mount Etna, Sicily. Bulletin of Volcanology, 49, $527-540$.

GRIFFITHS, R. W. 2000. The dynamics of lava flows. Annual Review of Fluid Mechanics, 32, 477-518.

HARRIS, A. J. L. \& Rowland, S. K. 2001. FlOWGO: a kinematic thermo-rheological model for lava flowing in a channel. Bulletin of Volcanology, 63, 20-44.

Harris, A., BAiley, J., CAlvari, S. \& DEHN, J. 2005. Heat loss measured at a lava channel and its implications for down-channel cooling and rheology. Geological Society of America Special Paper, 396, 125-146.

Harris, A. J. L., Dehn, J. \& Calvari, S. 2007. Lava effusion rate definition and measurement: a review. Bulletin of Volcanology, 70, 1-22.

Harris, A. J. L., Flynn, L. P., Matías, O. \& Rose, W. I. 2002. The thermal stealth flows of Santiaguito: implications for the cooling and emplacement of dacitic block lava flows. Geological Society of America Bulletin, 114, 533-546.

Harris, A. J. L., Flynn, L. P., Matías, O., Rose, W. I. \& Cornejo, J. 2004. The evolution of an active silicic lava flow field: an ETM+ perspective. Journal of Volcanological and Geothermal Research, 135, 147-168.

Heliker, C. \& Mattox, T. N. 2003. The first two decades of the $\mathrm{Pu}^{\prime} \mathrm{u}$ ' $\mathrm{O}^{\circ} \mathrm{o}-$ Kupaianaha eruption: chronology and selected biography. USGS Professional Paper, 1676, 1-27.

Helz, R. T., Heliker, C., Hon, K. \& Mangan, M. 2003. Thermal efficiency of lava tubes in the $\mathrm{Pu}$ ' $\mathrm{u}$ 'O'o-Kupaianaha eruption. USGS Professional Paper, 1676, 105-120.

Holman, J. P. 1992. Heat Transfer. McGraw Hill, London.

IsHiHARA, K., IGUCHI, M. \& KAMO, K. 1990. Numerical simulation of lava flows on some volcanoes in Japan. In: FinK, J. H. (ed.) Lava Flows and Domes. Springer, Berlin, 174-207.

JEFFREYS, H. 1925. Flow of water in an inclined channel of rectangular section. Philosophical Magazine Journal of Science, 49, 793-807.

Kauahikaua, J., Cashman, K. V., Hon, K., Mattox, T. N., Heliker, C. C., Mangan, M. T. \& ThORnBer, C. R. 1998. Observations of basaltic lava streams in tubes from Kilauea volcano, island of Hawaii. Journal of Geophysical Research, B103, 27,303-27,323.

Keszthelyi, L. 1995. A preliminary thermal budget for lava tubes on the Earth and planets. Journal of Geophysical Research, 100, 20,411-20,420.

Keszthelyi, L. \& Denlinger, R. 1996. The initial cooling of pahoehoe flow lobes. Bulletin of Volcano$\log y, \mathbf{5 8}, 5-18$.

Keszthelyi, L. \& Self, S. 1998. Some physical requirements for the emplacement of long basaltic lava flows. Journal of Geophysical Research, 103, 27,447-27,464.

Keszthelyi, L., Harris, A. J. L. \& Dehn, J. 2003. Observations of the effect of wind on the cooling of active lava flows. Journal of Geophysical Research, 30, SDE 4-1, 4-4.

Keszthelyi, L., McEwen, A. S. \& Thordarson, T. 2000. Terrestrial analogs and thermal models for Martian flood lavas. Journal of Geophysical Research, 105, 15,027-15,049.

KilbURN, C. R. J. 2000. Lava flows and flow fields. In: Sigurdsson, H., Houghton, B., Rymer, H. \& STIX, J. (eds) Encyclopedia of Volcanoes. Academic Press, London, 291-305.

Kilburn, C. R. J. \& Lopes, R. M. C. 1988. The growth of aa lava fields on Mount Etna, Sicily. Journal of Geophysical Research, 93, 14,759-14,772.

Klingelhofer, F., Hort, M., Kumpel, H.-J. \& SchmincKe, H.-U. 1999. Constraints on the formation of submarine lava flows from numerical model calculations. Journal of Volcanological and Geothermal Research, 92, 215-229.

LyMAN, A. W., KerR, R. C. \& Griffiths, R. W. 2005. Effects of internal rheology and surface cooling on the emplacement of lava flows. Journal of Volcanological and Geothermal Research, 110, B08207; doi:10.1029/2005JB003643.

Macdonald, G. A. 1963. Physical properties of erupting Hawaiian magmas. Geological Society of America Bulletin, 74, 1071-1078.

Malin, M. C. 1980. Lengths of Hawaiian lava flows. Geology, 8, 306-308.

MANLEY, C. R. 1992. Extended cooling and viscous flow of large, hot rhyolite lavas: implications of numerical modeling results. Journal of Geophysical Research, 53, 27-46.

Mattox, T. N., Heliker, C., Kauahikaua, J. \& Hon, K. 1993. Development of the 1990 Kalapana flow field, Kilauea Volcano, Hawaii. Bulletin of Volcano$\log y, \mathbf{5 5}, 407-413$.

MiYAмото, N. \& SASAKI, S. 1997. Simulating lava flows by an improved cellular automata method. Computers \& Geosciences, 23, 283-292.

Murray, J. B. \& Stevens, N. 2000. New formulae for estimating lava flow volumes at Mt. Etna Volcano, Sicily. Bulletin of Volcanology, 61, 515-526.

NiCHOLS, R. L. 1936. Flow-units in basalt. Journal of Geology, 44, 617-630.

OpPenHEIMER, C. 1991. Lava flow cooling estimated from Landsat Thematic Mapper infrared data: the Lonquimay eruption (Chile, 1989). Journal of Geophysical Research, 96, 21,865-21,878. 
Peterson, D. W., Holcomb, R. T., Tilling, R. I. \& Christiansen, R. L. 1994. Development of lava tubes in the light of observations at Mauna Ulu, Kilauea volcano, Hawaii. Bulletin of Volcanology, 56, 343-360.

PIERI, D. C. \& BALOGA, S. M. 1986. Eruption rate, area, and length relationships for some Hawaiian lava flows. Journal of Volcanological and Geothermal Research, 30, 29-45.

Pinkerton, H. \& Sparks, R. S. J. 1976. The 1975 sub-terminal lavas, Mount Etna: a case history of the formation of a compound lava field. Journal of Volcanological and Geothermal Research, 1, 167-182.

Pinkerton, H. \& Wilson, L. 1994. Factors effecting the lengths of channel-fed lava flows. Bulletin of Volcanology, 56, 108-120.

Quareni, F., Tallarico, A. \& Dragoni, M. 2004. Modeling of the steady-state temperature field in lava flow levees. Journal of Volcanological and Geothermal Research, 132, 241-251.

Romano, R. \& Sturiale, C. 1982. The historical eruptions of Mt. Etna. Memorie della Società Geologica Italiana, 23, 75-97.

Rowland, S. K. \& Walker, G. P. L. 1990. Pahoehoe and aa in Hawaii: volumetric flow rate controls the lava structure. Bulletin of Volcanology, 52, 615-628.

Rowland, S. K., GARBIEL, H. \& HARRIS, A. J. L. 2005. Lengths and hazards from channel-fed lava flows on Mauna Loa, Hawai'i, determined from thermal and downslope modeling with FLOWGO. Bulletin of Volcanology, 67, 634-647.

Rowland, S. K., HarRis, A. J. L. \& Garbeil, H. 2004. Effects of Martian conditions on numerically modeled, cooling-limited, channelized lava flows. Journal of Geophysical Research, 109, E10010; doi:10.1029/ 2004JE002288, 1-16.

SAKimoto, S. E. H. \& ZUber, M. T. 1998. Flow and convective cooling in lava tubes. Journal of Geophysical Research, 103, 27,465-27,487.

Sutton, A. J., Elias, T. \& Kauahikaua, J. 2003. Lava-effusion Rates for the $P u^{\prime} u$ ' $O{ }^{\prime} o-K u p a i a n a h a$
Eruption Derived from $\mathrm{SO}_{2}$ Emissions and Very Low Frequency (VLF) Measurements. USGS Professional Papers, 1676, 137-148.

Swanson, D. A. 1973. Pahoehoe flows from the 19691971 Mauna Ulu eruption, Kilauea volcano, Hawaii. Geological Society of America Bulletin, 84, 615-626.

Vicari, A., Alexis, H., Del Negro, C., Coltelli, M. Marsella, M. \& Proietti, C. 2007. Modeling of the 2001 lava flow at Etna volcano using a cellular automata approach. Environmental Modelling \& Software, 22, 1465-1471.

WADGE, G. 1978. Effusion rate and the shape of aa lava flow-fields on Mount Etna. Geology, 6, 503-506.

WADGE, G. 1981. The variation of magma discharge during basaltic eruptions. Journal of Volcanology and Geothermal Research, 11, 139-168.

WAdGe, G., Young, P. A. V. \& McKendrick, I. J. 1994. Mapping lava flow hazards using computer simulation. Journal of Geophysical Research, B99, 489-504.

WAlker, G. P. L. 1967. Thickness and Viscosity of Etnean Lavas. Nature, 213, 484-485.

WALKER, G. P. L. 1972. Compound and simple lava flows and flood basalts. Bulletin of Volcanology, 35, 579-590.

Walker, G. P. L. 1973. Lengths of lava flows. Philosophical Transactions of the Royal Society, London, 274, 107-118.

WitTER, J. B. \& HARRIS, A. J. L. 2007. Field measurements of heat loss from skylights and lava tube systems. Journal of Geophysical Research, 112, B01203; doi:10.1029/2005JB003800.

Wright, R., FlynN, L. P. \& HARRIS, A. J. L. 2001. The evolution of lava flow-fields at Mount Etna, 27-28 October 1999, observed by Landsat 7 ETM +. Bulletin of Volcanology, 63, 1-7.

ZHANG, Y., ZHENGJIU, X. \& YANG, L. 2003. Viscosity of hydrous rhyolitic melts inferred from kinetic experiments, and a new viscosity model. American Minerologist, 88, 1741-1752. 